Article

\title{
Life Cycle Engineering 4.0: A Proposal to Conceive Manufacturing Systems for Industry 4.0 Centred on the Human Factor (DfHFinI4.0)
}

\author{
Susana Suarez-Fernandez de Miranda 1,* , Francisco Aguayo-González ${ }^{1}$, Jorge Salguero-Gómez ${ }^{2}$ \\ and María Jesús Ávila-Gutiérrez ${ }^{1}$ \\ 1 Design Engineering Department. University of Seville, Polytechnic School, 41011, Seville, Spain; \\ faguayo@us.es (F.A.-G.); mavila@us.es (M.J.A.-G.) \\ 2 Mechanical Engineering and Industrial Design Department. University of Cádiz. Avenida de la \\ Universidad no 10, 11519, Puerto Real, Cádiz, Spain; jorge.salguero@uca.es \\ * Correspondence: ssuarez1@us.es
}

Received: 28 May 2020; Accepted: 25 June 2020; Published: 27 June 2020

\begin{abstract}
Engineering 4.0 environments are characterised by the digitisation, virtualisation, and connectivity of products, processes, and facilities composed of reconfigurable and adaptive socio-technical cyber-physical manufacturing systems (SCMS), in which Operator 4.0 works in real time in VUCA (volatile, uncertain, complex and ambiguous) contexts and markets. This situation gives rise to the interest in developing a framework for the conception of SCMS that allows the integration of the human factor, management, training, and development of the competencies of Operator 4.0 as fundamental aspects of the aforementioned system. The present paper is focused on answering how to conceive the adaptive manufacturing systems of Industry 4.0 through the operation, growth, and development of human talent in VUCA contexts. With this objective, exploratory research is carried, out whose contribution is specified in a framework called Design for the Human Factor in Industry 4.0 (DfHFinI4.0). From among the conceptual frameworks employed therein, the connectivist paradigm, Ashby's law of requisite variety and Vigotsky's activity theory are taken into consideration, in order to enable the affective-cognitive and timeless integration of the human factor within the SCMS. DfHFinI4.0 can be integrated into the life cycle engineering of the enterprise reference architectures, thereby obtaining manufacturing systems for Industry 4.0 focused on the human factor. The suggested framework is illustrated as a case study for the Purdue Enterprise Reference Architecture (PERA) methodology, which transforms it into PERA 4.0.
\end{abstract}

Keywords: life cycle; knowledge- and technology-intensive industry (KTI); manufacturing; VUCA; key enabling technology (KET); Operator 4.0; cyber-physical system (CPS); DfHFinI4.0; PERA 4.0

\section{Introduction}

Manufacturing processes are becoming increasingly automated and connected within companies. This means that the engineer has to acquire new competencies related to planning [1] and process management in VUCA (volatile, uncertain, complex and ambiguous) contexts [2], in both the manufacturing field and in the market. Due to these challenges in Industry 4.0, it is necessary to develop new competencies and improve existing competencies, for engineering students, as well as for professionals who have to design, manufacture, and manage interconnected smart products and processes. This requires the identification and development of training activities associated to the complex and creative characteristics of environments 4.0. These training activities are made possible by the potential of the interactions of digital enablers, and are integrated into the tasks to be carried out, whose main feature is the exchange of knowledge in real time. 
Manufacturing systems 4.0 [3] have to be provided, not only with adaptability to VUCA contexts in their technological, economic, environmental, and social aspects, but also in a sustainable manner, so that, depending on the purpose established by the market [4], the system can co-evolve in a stable way. This entails a continuous evolution of the competencies associated to Operators 4.0, in order to deal successfully with increasingly complex and creative problems [5]. The aforementioned evolution of the competencies associated with Operators 4.0 gives rise to the interest in conceiving socio-technical cyber-physical manufacturing systems (SCMS), in which the processes and relationships between human and technological factors are integrated and can co-evolve, which is crucial in the management, development, and growth of smart factories and learning factories. This interaction of the human factor with machines and robots acquires major importance in these factories through interfaces based on cognitive and neurocognitive technologies.

The adjustment in the field of design and production management between manufacturing systems and Operators 4.0 [6] can be supported by cyber-physical systems, and from the possibilities offered by key enabling technologies (KETs) and new frameworks. The aforementioned lack of adjustment provokes the need for engineers and technicians to be trained as managers of the digital transformation by updating their knowledge and competencies with online support through interfaces that enable connection in workflows. The digital transformation process constitutes a key element that places the human factor at the centre of Industry 4.0, by creating integrated and co-evolutionary systems that take into account the work environment and the marketplace [7]; these systems are herein labelled SCMS.

The foregoing constitutes a research potential in which contributions have been made that refer to general aspects of the organisation of Industrial 4.0 [8-10], and others aspects related to the integration of Operator 4.0 within the socio-technical systems of Industry 4.0 [11-21].

This paper focuses on the life cycle engineering of manufacturing systems for Industry 4.0 [22-24], and the potential of KETs and the variety required thereof for the integration of Operators 4.0 towards the growth and development of such systems. In this paper, a new framework called Design for the Human Factor in Industry 4.0 (DfHFinI4.0) is therefore proposed, which allows the human factor to be placed at the core of Industry 4.0 and is based on the conceptual frameworks of the connectivist paradigm, the law of requisite variety, and on activity theory. Its main contribution lies in the modelling of SCMS from the consideration of the relationships between the human and technological factors (equipment and information system). This consideration enables the transfer of routine and smart competencies from human operators to the technical systems and takes full advantage of the engineer's talent by encouraging competencies of greater scope derived from the incorporation of KETs. All this brings added value to the management of the engineering processes, technologies, and competencies required in the different phases of the life cycle of smart and learning factories, and ensures the adaptation of products and processes to market dynamics [25].

The goal of this paper involves responding to the problem of conceiving cyber-physical socio-technical manufacturing systems from socio-cognitive conceptual frameworks under the perspective of life cycle engineering, in which the growth and development of the talent of Operators 4.0 is made possible. This research objective, yet to be put into practice, constitutes exploratory research, with a qualitative approach, and uses deductive methodology, in which the DfHFinI4.0 framework is formulated from conceptual frameworks identified with bibliographic review techniques [26], whose feasibility is explored in the inclusion proposal for the Purdue Enterprise Reference Architecture (PERA) architecture and methodology.

In the design and application of the proposed methodology, the following steps can be distinguished:

- $\quad$ First, the state of the art is analysed to identify the gap.

- The conceptual frameworks are then presented and analysed to value their usefulness in the resolution of the formulated gap.

- The proposed framework is designed while taking the inclusion of the previous conceptual frameworks into consideration.

- Finally, the method is applied to a case study. 
The conception of SCMS considering the perspective of life cycle engineering enables the work systems of the engineer and technicians to be configured as Operators 4.0, through the integration of all aspects associated with professional competence for their operational and effective efficiency [27], which permits the gap between human and technological factors to be bridged. Regarding these SCMS, the navigation by the Operator 4.0, through the cyber-physical space, is managed by the interfaces, and the associated training actions are adjusted for the acquisition of higher levels of experience and professionalism. All this fosters progressive adaptation from the academic to the professional field and career development. The proposed DfHFinI4.0 framework can be integrated into various life cycle engineering methodologies of smart and learning factories. A case study for the PERA methodology has been implemented in cyber-physical systems and is configured as PERA 4.0.

The organisation of the paper is structured as follows: Section II contextualises and considers the aspects related to smart manufacturing, while paying particular attention to the cyber-physical systems (CPS), for its projection in the conceptualisation of SCMS. Section III describes the conceptual domains that are employed to obtain SCMS. In Section IV, the conceptual domains are articulated in a DfHFinI4.0 framework, which allows the configuration of integrated and co-evolutive SCMS, and establishes the relationships between its elements. Section V applies the proposed framework to the PERA methodology, thereby transforming it into PERA 4.0. Section VI lays out the discussion and proposes future work. Finally, Section VII presents the conclusions.

\section{Background of the Literature}

In this section, from among the possible types of reviews characterised by Mayer [26], a status quo review is carried out that entails a description of the state of knowledge in smart manufacturing, especially regarding cyber-physical systems in Industry 4.0. The content of the review has been graphically represented, as shown in Figure 1. The result of the review will allow us to characterise different aspects of SCMS and the gap associated to the human factor.

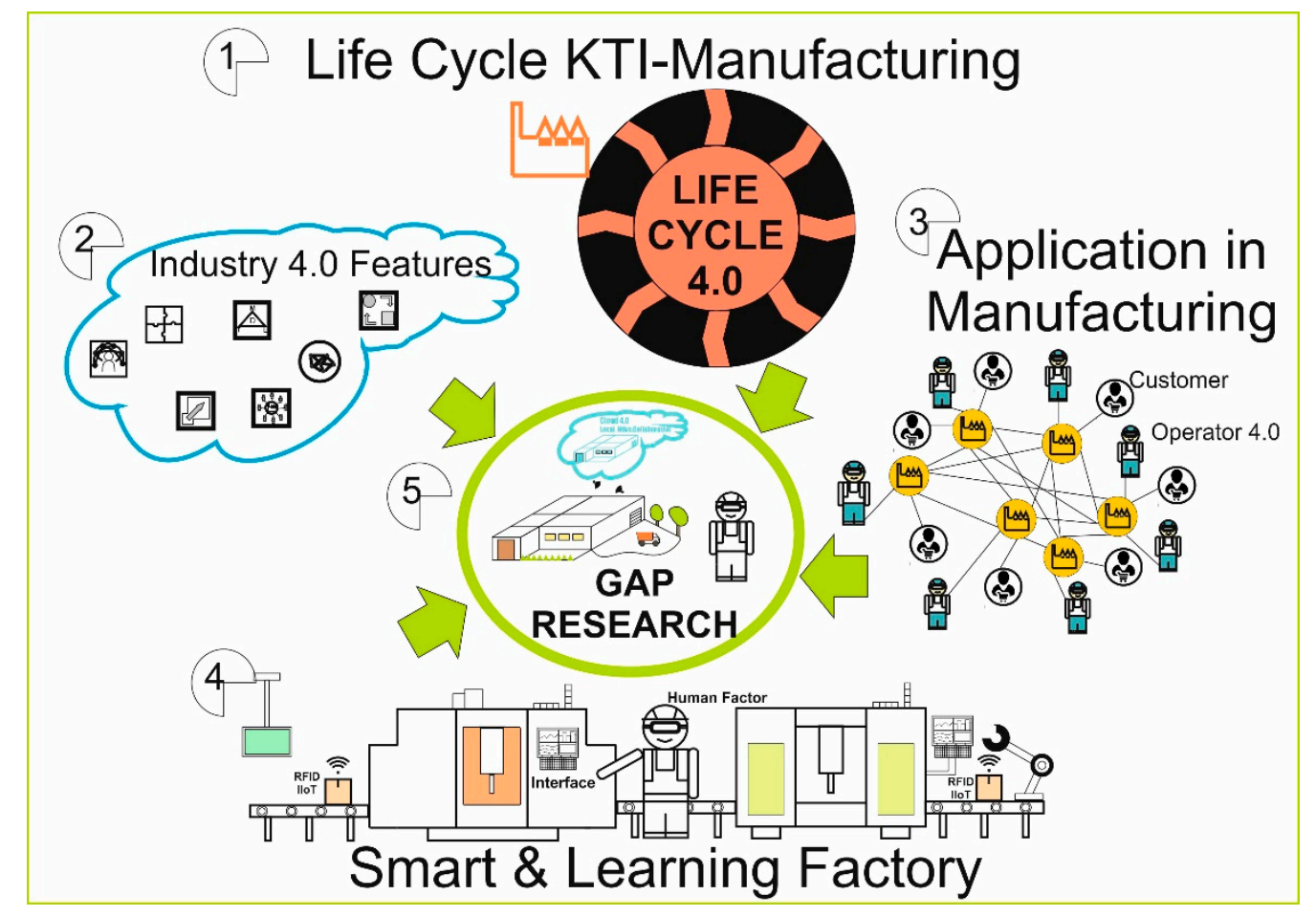

Figure 1. Background of the literature organisation.

\subsection{Life Cycle Knowledge- and Technology-Intensive Industry (KTI) Manufacturing}

The Organisation for Economic Co-operation and Development (OECD) taxonomy classifies the industries into five groups (high, medium-high, medium, medium-low, and low), and includes 
all the manufacturing industries in the high and medium categories [28]. Knowledge- and technology-intensive industries (KTIs) are those that have a particularly strong link to science and technology, and are classified by the OECD taxonomy as high- and medium-intensive R\&D industries. Aerospace, computers and office machinery, testing instruments, pharmaceuticals, motor vehicles, chemicals, machinery and equipment, business, communications, and education constitute knowledge- and technology-intensive industries (KTIs) [29].

The evolution of automation, given the possibilities presented by digital enablers, connectivity and artificial intelligence, has made possible the inclusion of knowledge in a wide variety of cyber-physical elements [15], by proposing areas of research in which the distribution of knowledge and intelligence between Operators 4.0 and technological solutions is produced, not only with the assistance of KETs [30], but also by cognitive capabilities [9]. Another area of research [31] of great significance for the present work is related to the personalisation of technology and occupational environments that use subrogate models of Operators 4.0 to parameterise the adaptation of the technology, thanks to their ability to conceptualise and consider them as another cyber-physical system of the SCMS.

Within the framework of Industry 4.0, the life cycle engineering of manufacturing systems, together with the concept of cyber-physical systems of technical equipment, includes the concept of Operator 4.0 [32]. Its differential features include creative intelligence and expertise in the domain of knowledge that constitutes the field of responsibility. Their modes of operation in Industry 4.0 environments are performed cooperatively with robots and machines, and with cyber-physical resources, and employ advanced human-machine interaction technologies and adaptive automation to achieve a suitable degree of symbiosis [11-33]. Collaborative robots enable the creation of shared work environments where productivity can increase while minimising delivery response time [34], and developing tasks cooperatively to solve open or complex problems under creative approaches that are representative of VUCA contexts. This provides evidence that environments based on the combination of human and technological factors can successfully tackle such contexts [35].

On the one hand, all the challenges that characterise the smart manufacturing process require continuous innovation and learning [36]. Distributed manufacturing is supported by a real-time operation planning system that controls manufacturing networks [37]. Manufacturing processes are becoming increasingly automated and connected within organisations [1]. Complexity and flexibility in manufacturing require analytics, efficient problem-solving, and process improvements. Business intelligence (BI) analysis graphs represent expert knowledge on analysis processes [38]. Manufacturing involves collaborative information exchange from several sources under different working conditions [39]. The concept of collective intelligence has been applied in engineering within the field of cyber-physical systems (CPS). Knowledge is used by automated problem-solving methods to coordinate and supervise manufacturing systems. Ontology can thereby play a major role in the process of creating and managing knowledge [40]. On the other hand, lean manufacturing is a management model that focuses on minimising losses and optimising the creation of value for the client. Enke et al. [14] take into consideration the combination of lean manufacturing and Industry 4.0. Lean-based methodologies can improve organisational capabilities and tools to facilitate the transformation of a company into Industry 4.0 [41]. The concepts of lean manufacturing and Industry 4.0 can be developed in an end-to-end value chain for the Learning Factory to learn how to carry out a digital transformation [42].

\subsection{Industry 4.0 Features}

Among the characteristics of Industry 4.0 systems, boundaries between operation technologies (OT) and information technologies (IT) are disappearing [43]. Visualisation technologies, and fundamentally augmented [16], virtual and mixed reality are incorporated into production processes and training, since it has been proven that these constitute useful tools for Industry 4.0 [17,35]. Previously established immersion technologies [44], as well as brain-computer interfaces and brain-machine interfaces, improve manufacturing systems [45] and Operator 4.0 performance [35]. 
Several models and definitions, such as reconfigurable manufacturing systems, smart factories, and ubiquitous factories, are associated with Industry 4.0 [46]. The complexity and flexibility in which companies and engineers have to operate in these environments require analysis [10], efficient problem-solving, and process improvement. The use of business intelligence (BI) analysis charts represents expert knowledge for analysis processes and provides support in the work carried out by the engineer [38], from the engineering perspective of the life cycle 4.0, in cyber-physical systems design, development, and management environments [47].

In Industry 4.0 systems, the customisation of products, processes, and services requires flexibility in the manufacturing and intelligence for smart products. It is also possible to enable the integration of ontology-based web services for flexible manufacturing systems [48]. Semantic web technologies can be used with cybernetic systems to integrate the decision-making process into smart machinery [49]. This allows automated decisions to be made, to help in the configuration of the manufacturing system from its representation of a virtual or digital twin. Therefore, ontology can play a major role in the process of creating and managing knowledge of cyber-physical systems [40].

One critical aspect of Industry 4.0 relative to advanced manufacturing is that of the availability of real-time information to optimally program the objectives of manufacturing systems throughout systems that have edge, fog, and cloud architecture [50]. Qu et al. [51] propose an ontology-based framework to represent a synchronised and station-based flow workshop, and develop a multi-agent reinforcement learning approach for optimal programming.

In order to apply simulation solutions that improve the efficiency and profitability of Industry 4.0 systems, digital twins are created to describe the behaviour of the system. Stark, Kind and Neumeyer [47] consider the digital twin as the digital representation of a product, machine, service, product service system, or other intangible assets, that alters their properties, conditions, and behaviour, through models, information, and data. This concept is not only restricted to the operational part, however: it is also transposed to the human component [18] by generating a digital twin for the Operator 4.0 [31]. Recent developments in machine learning and other big data techniques offer new possibilities in conjunction with the concept of a digital twin [52] and subrogated models.

\subsection{Application in Manufacturing}

Relevant themes that have emerged as a result of flexibility, customisation, optimisation (saving time and costs), and smartisation, and those that require increasing connectivity include: predictive maintenance, which serves the objectives of sustainable manufacturing in the three dimensions of 3E; virtual commissioning [53] and crowdsourced manufacturing organisations [54]; real-time online support for production operators; new opportunities for servitisation; co-design; and co-manufacturing, cloud manufacturing and social manufacturing [55].

The role of Industry 4.0 maintenance, especially that of predictive maintenance, presents a strategic factor in manufacturing [56]. Techniques, such as forecasting, health and safety management (PHM), and condition-based maintenance (CBM), create a demand for Operators 4.0 with adaptive interfaces that allow suitable characterisation and development of the required maintenance, with the necessary connectivity and the appropriate decision support [19]. The implementation of such techniques requires the use of the Industrial Internet of Things (IIoT) [40], cloud computing [57], big data [58], machine learning, and augmented reality [59,60]. In this respect, Cachada et al. [56] describe the architecture of intelligent and predictive maintenance to support Operators 4.0 by providing guided intelligent decision support.

Virtual commissioning, through the creation of a simulation model in a virtual environment of a manufacturing plant, allows Operator 4.0 to propose the necessary changes for its subsequent implementation in the real plant. However, today's lack of competencies and associated experiences hinder the full integration of this tool in manufacturing [53].

Crowdsourced manufacturing organisations share their manufacturing resources based on their demand and capacity. Kaihara et al. [54] have developed a manufacturing simulation model in 
collaboration with a resource model and a negotiation algorithm based on cyber-physical systems to evaluate the effectiveness of manufacturing. This enables Operator 4.0 to cover the task of resource manager and requires interfaces capable of providing real-time feedback on shared resources and on any needs that may arise.

\subsection{Smart and Learning Factories}

The new professional engineer profiles that have emerged in Industry 4.0 environments require a suitable characterisation of the competencies to be acquired [20,61], in order to interact with smart manufacturing agents. To this end, the learning factories have been developed and are employed to instruct and train engineers through an approach between learning and professional practice, thereby contextualising Industry 4.0 environments. Furthermore, learning factories enable applied research to be carried out, both in engineering areas and in other areas of interest [8,21], and also foster collaboration between companies, students, and universities [62], with dual training models.

For successful operations in smart and learning factories, not only must training in technical competencies be taken into account, but also training in solving complex problems with uncertainty and decision-making in real time, under time pressure [63]. Special attention should be given to the acquisition of creative competencies, innovation, multicultural teamwork, and the ability to solve complex problems, all as enablers for their operation in VUCA contexts [61]. Research studies are currently being carried out in which transformation processes are developed in a manufacturing workshop, led by training in a learning factory, which involves instruction, integration, and engineering. This instruction is related to training strategies and objectives [64], in which serious gaming instructional techniques are incorporated, which can be employed to develop competencies related to new technologies in Industry 4.0 [65].

A smart factory [66] is made up of cyber-physical systems consisting of a physical part and an associated digital twin, with great possibilities for connectivity, intelligence, and data processing in the cloud and in the fog, and for operation with subrogate models [50]. These operational environments determine the need for tools that integrate the potential of the competencies acquired by the engineer with the use of technologies 4.0 [64]. In this context, Operator 4.0 constitutes a cyber-physical system with the possibility of multiscale and multilevel connectivity, with great analytical, calculation, and simulation capacity.

The development of learning factories, which allows the introduction of the concept of a digital twin and its applications, is necessary not only at the level of large companies, but also for SMEs (small and medium-sized enterprises) $[13,67]$. This leads to the integration of all the possible business fabric within the concept of Industry 4.0, whatever the size of the company.

\subsection{Research Gap}

Once the review of the most specific research parameters of Industry 4.0 and its manufacturing systems has been carried out, these parameters can then be characterised in a more detailed way as shown in Table 1, in order to establish a way in which to conceive the adaptive manufacturing systems of Industry 4.0, through the operation, growth, and development of human talent in VUCA environments. In this table, those papers that are most relevant for their contribution towards adaptive manufacturing through synergistic actions of processes, technology, and human factors in SCMS, characterise the research gap.

The contributions of those various studies whose objective involves the integration of technological enablers and their potential for adaptive manufacturing have been examined, both for exogenous changes (external client and contextual factors) and for internal changes (internal client and contextual factors). Identification has been made of the need for: conceptual resources and frames that allow the analysis of the productive activity located at any level of granularity; the search for allostasis (dynamic balance) between technology, processes, and Operator 4.0; and for the leverage of human talent and its affective coupling to manufacturing systems. In the following section, conceptual frameworks are presented that lead to the synergistic and adaptive manufacturing system framework proposed in the paper. 
Table 1. Specific research parameters of Industry 4.0 and its manufacturing systems.

\begin{tabular}{|c|c|c|c|c|c|c|}
\hline \multicolumn{7}{|c|}{ Adaptative Manufacturing } \\
\hline & D1 & D2 & D3 & D4 & D5 & D6 \\
\hline$[8]$ & $x$ & - & $\checkmark$ & $x$ & - & $\checkmark$ \\
\hline [9] & - & $\checkmark$ & - & $x$ & $\checkmark$ & $x$ \\
\hline [10] & $x$ & $\checkmark$ & - & $x$ & - & - \\
\hline [11] & $x$ & $\checkmark$ & $\checkmark$ & - & - & - \\
\hline [12] & $x$ & - & $\checkmark$ & $x$ & $\checkmark$ & $x$ \\
\hline [13] & $x$ & $\checkmark$ & - & $x$ & $x$ & $x$ \\
\hline [14] & $x$ & - & - & $x$ & $x$ & $\checkmark$ \\
\hline [15] & $x$ & - & - & - & - & $x$ \\
\hline [16] & $x$ & - & $x$ & - & $x$ & $x$ \\
\hline [17] & $x$ & $\checkmark$ & - & $\checkmark$ & $x$ & $x$ \\
\hline [18] & $x$ & - & $x$ & $\checkmark$ & - & $\checkmark$ \\
\hline [19] & $x$ & - & $x$ & $\checkmark$ & - & $x$ \\
\hline [20] & $x$ & $\checkmark$ & - & $x$ & - & $x$ \\
\hline [21] & $x$ & - & $x$ & - & $\checkmark$ & $x$ \\
\hline
\end{tabular}

The levels considered are: $(\mathbf{x})$ minor level, (-) medium level and $(\checkmark)$ mayor level. D1: Modelling and simulation of SCMS. D2: Assistance in decision-making and navigation strategies. D3: Soft and hard skills. D4: Affective interaction. D5: Cognitive, socio-cognitive and cultural ergonomics. D6: Competence management and talent development throughout the professional life cycle.

After this review of the literature, observation is made of the effort being carried out in the field of digital transformation for the application of key enabling technologies (KETs), as shown in Figure 2 , and of the implementation of SCMS, which enables successful operations in VUCA environments. The preceding situation modifies the bases of productivity and the competencies required to adapt to this new situation, in which the life cycles of products, manufacturing technology, and knowledge are becoming shorter and more volatile.

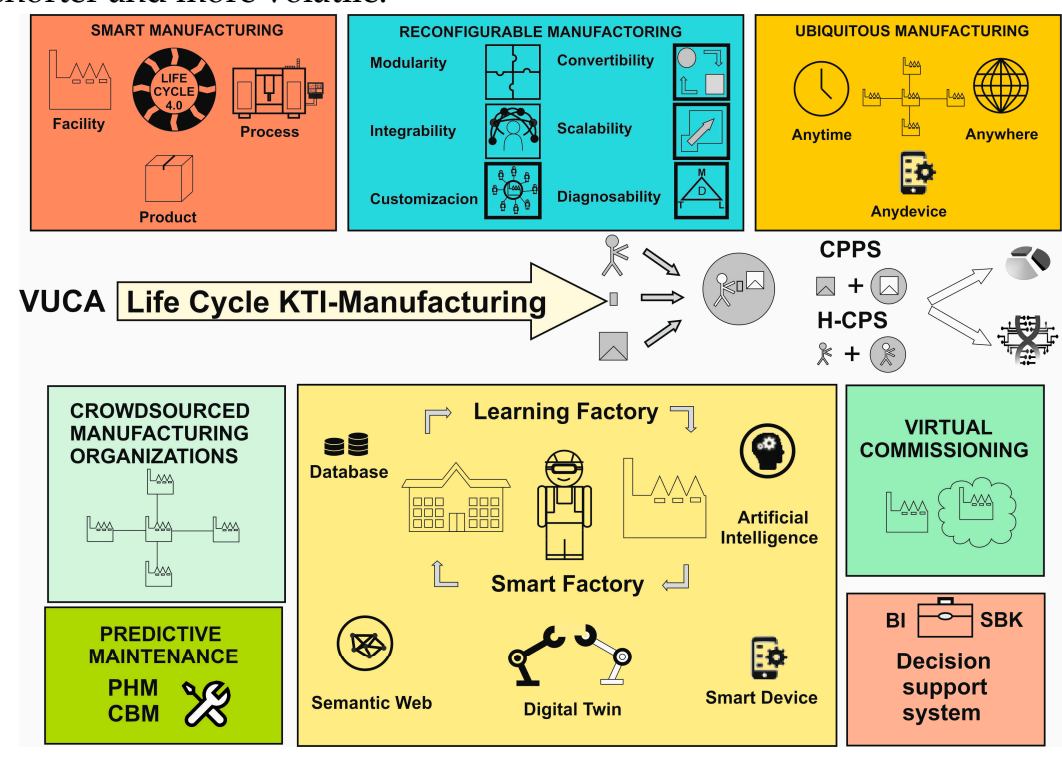

Figure 2. Application context for DfHFinI4.0.

Life cycle engineering 4.0 must be equipped with tools to integrate experience and to project human talent in the growth and development of SCMS from the opportunities of the operational environment. To this end, it is necessary to identify a set of conceptual frameworks that enable tools to be derived: for the conception of the work in the SCMS environment, in the most complete and possible way; to integrate the various elements therein, both individually and socially; and to assign tasks to the human and technological factors so that they work collaboratively by establishing adaptive interfaces. For this purpose, Vigosky's activity theory $[68,69]$ has been considered. 
Complementary to the decision to identify a conceptual framework for the formalisation of work in all dimensions of its complexity, its conception is required to integrate elements and solutions that allow its adaptation and self-regulation, depending on the operational, cognitive and affective variety of the Operators 4.0 that can undertake the job, thereby allowing its coupling to the established work system. Ashby's law of requisite variety has therefore been selected $[67,70]$, since it is integrated in the activity theory, which enables the self-regulation of tasks in accordance with the Operator 4.0 who develops it and with the affective connection required.

Finally, the further aspect of the human factor integration that requires special attention is that of the co-evolutionary development of the joint action of the socio-technical system which enables growth and development. This aspect provides online support strategies in the development of tasks and assistance in the growth and structuring of the experience acquired in the form of lessons learned, for their subsequent reuse in analogous situations, and consequently enables navigation strategies in the information system under semantic websites that allow the innovation and growth at both the individual and collective levels. To this end, the instructional framework of connectivism has been selected to derive strategies and tools [71,72].

Subsequently, these conceptual areas are structured in the proposed framework which is oriented towards the integration of the human factor within the environment of a smart company [73] which configures an SCMS, based on the search for the best available techniques, with the aim of seeking manufacturing excellence. All these techniques integrate, on the one hand, the potential of emerging conceptual frameworks; on the other hand, they integrate key digital and technological enablers, by merging the human and technological factors that correspond to the environment that produces them.

In the following section, the conceptual approaches and the KETs that will integrate the framework are presented, and an analysis is given of the most characteristic features that make them value drivers for the conception of the DfHFinI4.0 framework.

\section{Conceptual Frameworks}

The adaptation by companies to the requirements of Industry 4.0 entails the appropriate training of both engineers and technicians [42] that is focused on handling problems of a greater complexity and open situations of a wider scope, as depicted in Figure 3. The acquisition, training, and improvement of these competencies, defined in accordance with the updating of the tasks to be carried out Operator 4.0 and their relationship with the other elements of the SCMS, enable professional profiles to be generated in accordance with the requirements in the smart and learning factories [74]. This represents a major training challenge, both in the academic and professional fields [75]. The engineer, as Operator 4.0, has to be capable of handling interoperability, virtualisation, decentralisation, service orientation, modularity, and key technology enablers (KETs) [76]. 


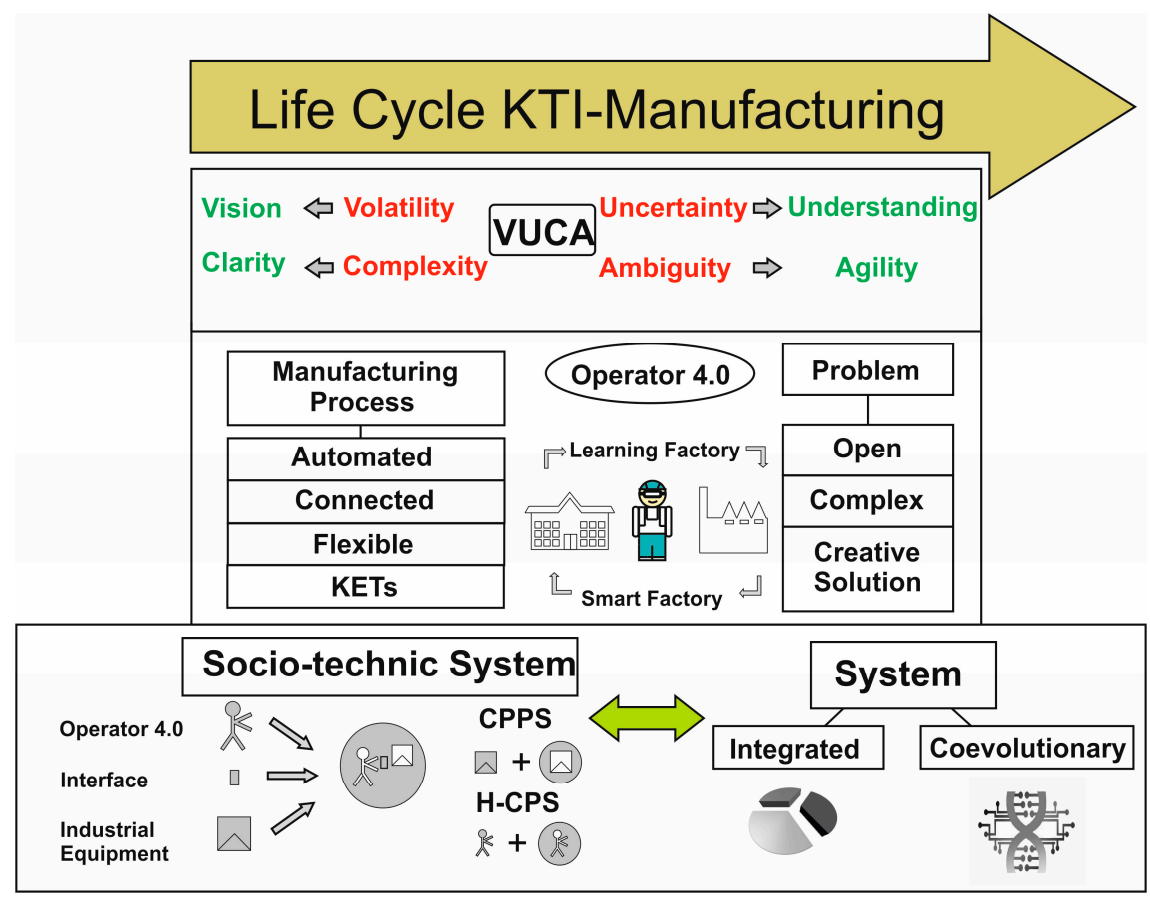

Figure 3. Smart Manufacturing requirements.

Along with the new demands of competencies required for workers, it is necessary to conceive the technology and associated processes of interaction with operators in Industry 4.0, as cognitive and socio-cognitive systems with affective connectivity. These characteristics make possible the integration and co-evolution of the SCMS formed by the human and technological factors under an organisational framework in the cultural context of a given company. Both factors, human and technological, are coupled [77] through adaptive interfaces that co-evolve as a cyber-physical system, together with Operator 4.0 and industrial equipment.

As shown in Figure 4., the potential from KETs triggers the search for a framework articulated in a toolbox that enables affect-socio-cognitive SCMS to be obtained, that respond to the different situations in which the engineer as an Operator 4.0 must be competent within an Industry 4.0 environment. This potential is articulated in conceptual frameworks derived from other areas of research: the theory of action [78]; the activity theory [79]; the required variety of Ashby for affective integration and coupling; and support in obtaining objectiveness and intentionality in the domains of cyber-physical entities through the connectivist paradigm:

- For the division of the labour to be performed by the engineer and technicians as Operators 4.0, the formalisation and analysis of its elements is carried out by Vigotsky's activity theory, as a tool that supports the elements of work, their variety, and the social fabric in which they are developed.

- The work to be carried out by engineers requires adaptation to their cognitive and affective characteristics, as well as to the particular characteristics of the task to be performed. Consequently, Ashby's law of requisite variety is employed, which is articulated in different elements and relationships of the activity theory.

- The establishment of the network workflow in real time, as well as the training required depending on the type of situation requested, are carried out by applying the connectivist methodology, which provides the supports and strategies of online navigation.

- The potential of these conceptual frameworks is implemented under the DfHFinI4.0 framework with KETs. 


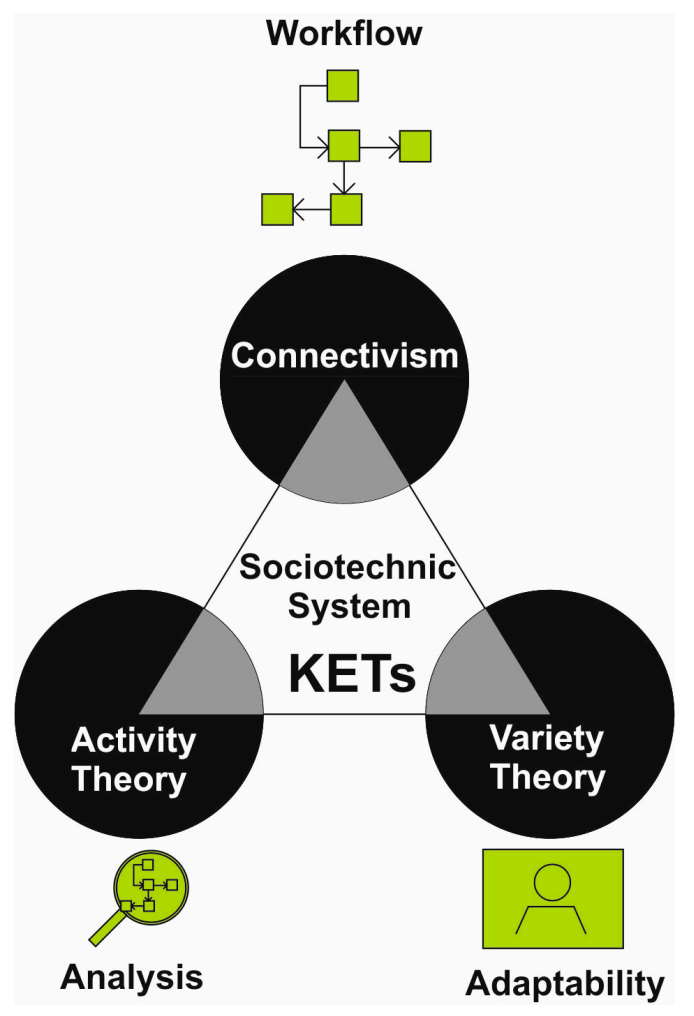

Figure 4. Conceptual frameworks that configure DfHFinI4.0.

The proposed DfHFinI4.0 framework requires the use of high-frequency trading concepts and technologies (HFTs) that are useful in modelling cyber-physical systems 4.0. A descriptive review of their state of knowledge based on Squires [80] is therefore proposed, which generates a proposal adapted to the field of smart manufacturing. In the following subsections, these various conceptual approaches are developed and articulated within this field.

\subsection{Activity Theory}

According to Vigotsky's activity theory, the action of the engineer as an Operator 4.0, which is represented in Figure 5, takes place in a SCMS [81], where the engineer with the interface solves problems or, with the help of a tool, transforms the raw material or the product [82] as a result of its application. The interaction between the human factor and machines and robots is mediated through interfaces [12], whereby the latter constitute the tools within the activity system [83]. The adoption of Vigotsky's activity theory as a unit of analysis for containing all its elements involved in work situations was reformulated by Yrjo Engeström [84]. This author has considered its evolution through three generations of research. Its use is especially significant as an instrument to model the activity and knowledge, that, in Industry 4.0, is largely transferred from technology to the human factor. 


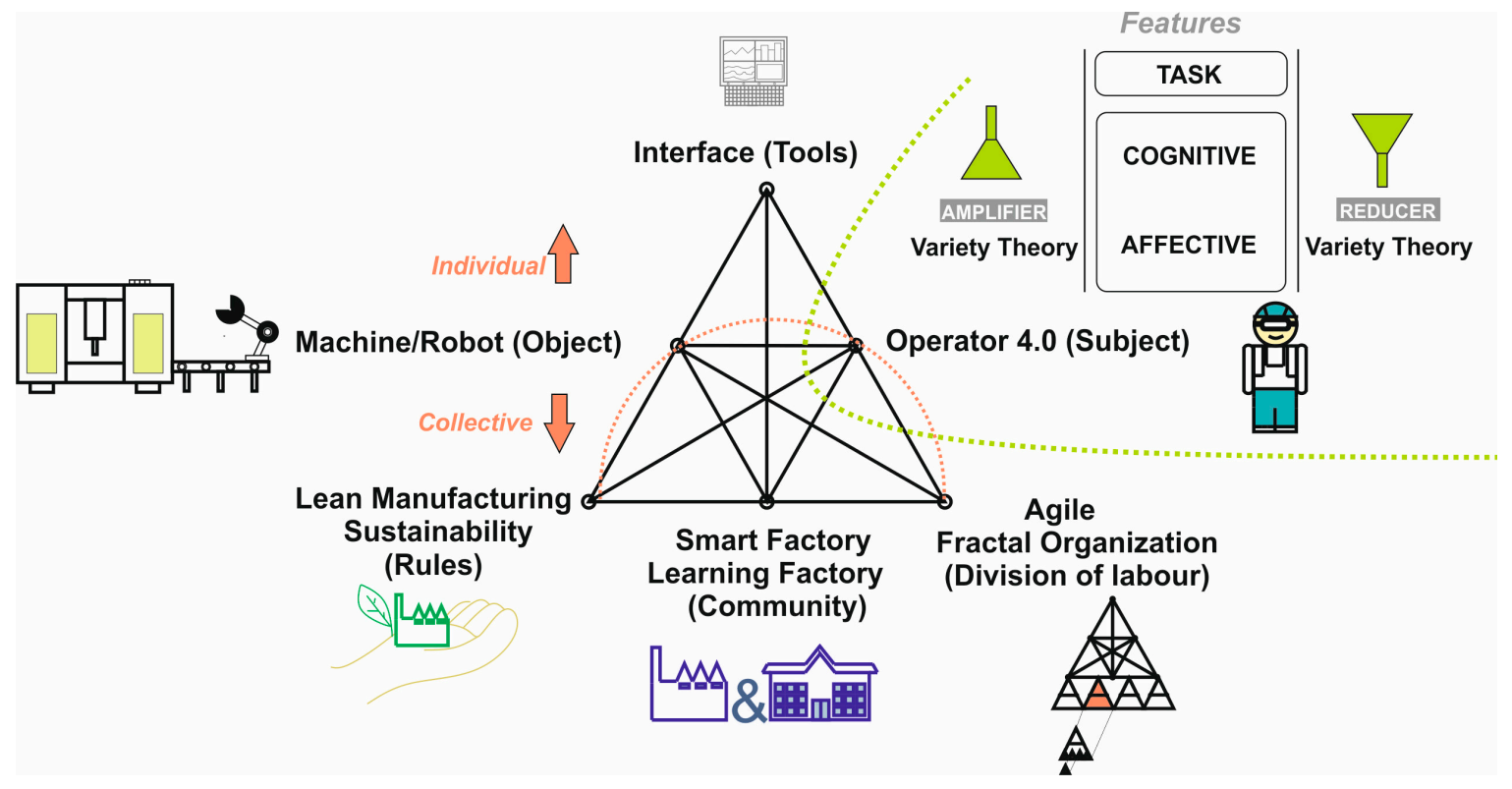

Figure 5. Activity theory and Law of requisite variety to model characteristics of Operator 4.0.

In the second generation of activity theory, Engeström expands the Vigotsky triangle to represent the collective elements of the activity system. From the Engeström model [85], it is possible to develop a general structure of the activity based on Operator 4.0, machines, robots, work equipment, interfaces, rules, and division of labour, as well as on the knowledge implicit in the technology (tool) and in the operator, and even in the evolution of their competencies as a consequence of the development of work. The rules and regulations, explicit and implicit, define the course of action to accomplish the task. The tasks are carried out according to the organisational structure of the company, through a division of labour. In the third generation of activity theory, tools are developed for dialogue, diversity of perspectives and networks of interacting activity systems. Modelling operational activity with activity theory enables the analysis to be performed with different granularity [86], and also the incorporation of the analysis of the different dimensions of the elements for the study of their integration and of the effect that arises from articulated solutions.

This theory has been applied, among other areas, in training organisation [87], human-computer interaction (HCI) [88], and information systems (IS) [89], since it has been proven to be a highly useful tool in the establishment of the way in which ICTs and other technologies interact with their context [90]. In this system of analysis of the proposed activity, the operator and the technological and organisational elements are interrelated [91], thereby enabling a holistic analysis of the socio-technical system. Its articulation in engineering has great potential for engineers to adapt to the requirements of smart and learning factories [92], when it comes to modelling and responding to training and co-evolution needs [93,94]. All this reduces the static and dynamic complexity in manufacturing systems regarding cyber-physical systems.

Activity theory [95] facilitates interactivity and assertive navigation, and encourages the engineer's creativity as an Operator 4.0, in the resolution of open and complex problems. This is made possible by enhancing not only cognitive competencies [96], but also affective coupling, since the latter enables better responses to be made to possible feedbacks, thereby facilitating the resolution of problems in collaborative work. In this respect, the same objective as that which the video game industry [97] demands from designers can be applied to smart manufacturing; an innovative design that attracts the attention of the internal customer (Operator 4.0), where there is constant feedback at the cognitive and affective level, which encourages constant engagement. This can be employed to design interfaces and the work system as a whole, with the aim of promoting its use through motivation [98], affectivity, dependency, and feedback generated by the engineer. 


\subsection{Law of Requisite Variety}

The work analysis requirements focused on the explicit and implicit knowledge that cyber-physical manufacturing systems must support, both for human and technological factors, to justify the incorporation of Vigotsky's activity theory as a tool to formalise the elements that integrate a work system, both in its individual and social dimension, with the aim of obtaining socio-cognitive manufacturing systems. By taking this theory into consideration, it is possible to identify various elements of the work and their features. Such is the case of Operators 4.0 and their associated competencies, the tools, products and problems on which they take part, the organisation and specialisation required for the work accomplished, in addition to the associated operational culture. Nevertheless, the aforementioned analysis suffers from the inclusion of mechanisms to identify, among others, sensory, cognitive, and affective capacities, and experience of the Operators 4.0 that will be assigned to a workstation and the required demands of the work system. This situation considers the need to identify a conceptual framework that enables the characterisation of the variety of competencies of workers and the work system demand with which they interact, and to determine their discrepancy and variety adaptation mechanisms. The aforementioned mechanisms and the affection that comes from their implementation must be represented in the activity theory for the articulation of mechanisms that allow the adaptation of the required variety of the technological system to the variety established in the worker.

In relation to this, given the need for a conceptual framework to adapt variety on the structure of the elements of the activity theory, it is worth considering Ashby's law of requisite variety [67]. This law establishes that a regulator-regulated system is one that is made up of a regulatory subsystem that exercises its action based on the information collected from the regulated subsystem [70]. In this kind of system, the regulatory part (work station, machine, robot, process) must have at least the same variety as the regulated part (Operator 4.0 or work equipment 4.0 ) so that the system reaches stability, which necessitates the establishment of a one-to-one correspondence between the varieties on each side. In order to achieve this adjustment, adapters are employed to reduce or amplify the variety, depending on what is required [99]. This adapter is itself a system or part of a system, and can act in either direction, increasing the variety by means of amplifiers or reducing it by means of reducers, until the regulator and regulated subsystems reach the same variety and determine an affective occupational use experience.

The adjustment of the collaborative environment to the engineers as Operators 4.0 [100] can be carried out by taking into account the law of variety (law of requisite variety), and will depend both on the constraints of the tasks to be performed [101] and on the cognitive [102] and affective [103] features possessed by the engineer and the technicians who operate in Industry 4.0, as illustrated in Figure 5 above.

Regarding the adaptation elements of the variety, in the context of Industry 4.0, it is necessary to consider the characteristics of the Operator 4.0 tasks, limited to situations of complex, creative problem-solving, with uncertainty and deadlines. This requires online support regarding knowledge, embodied in Operators 4.0, from the company's knowledge bases and other stakeholders in the project. All this determines that, as adaptation strategies of the variety of technology 4.0 (through interfaces, mobile devices, tablets, and wearables), the potential of KETs and the management of the variety required are utilised, so that the navigation strategies provide the online support required by the Operator 4.0.

As mentioned earlier, this enables the personalised occupational activity of Operators 4.0 to be modelled, who, in their implementation of achievements, determine the support of navigation strategies and of the dynamic management of the operational requirements, of their learning and improvement of competencies and of the reconfiguration of the technological environment 4.0 for the variety required according to the designated worker. In order to answer these questions, it is considered as a conceptual framework to manage the variety in the navigation strategies, learning support, and systematisation of lessons learnt in the connectivist paradigm [104], which will be presented with KETs. 


\subsection{Connectivist Paradigm}

In the field of smart manufacturing, connectivity acquires major importance in a cyber-physical environment, with the hybridisation of the physical and digital world, and with artificial intelligence and knowledge, not only in the cloud, but also integrated into production, equipment and tools in the edge. This has resulted in Operator 4.0 competencies moving towards complex and open creative, social, and problem-solving competencies, with opportunities for continuous learning. Support in the navigation strategies of Operator 4.0 is necessary for the resolution of problems; it is here where the connectivist theory of Stephen Downes and George Siemens intervenes, which affects the process of connecting specialised knowledge [105,106], under the theoretical principles of the Clark and Chalmers concept of the extended mind [107].

A crucial component of this connectivity falls on the semantic web as the informational dimension of the extended mind [108]. On the one hand, the semantic web is an intelligent entity that generates, shares, and connects content, capable of being interpreted by operators, machines and robots, to work collaboratively through specific languages such as XML, RDF, RDFS, OWL. It enables the articulation of connectivist schemes for the online support of navigation strategies in problem-solving, learning, collaboration, and systematisation of the experience. This semantic web enables the meaning of this data to be interpreted in a similar way to that of the semantic analysis of the operator's language and therefore to support the workers in their various tasks. It provides communication content between Operator 4.0 and machines and robots with semantic content, and allows the information to be processed based on a semantic assessment of its content, which permits its best coupling through interfaces so that it can be optimally interpreted by the engineer [49]. On the other hand, the use of ontologies in the semantic web enables the correct identification of the meaning of instructions according to a given situation and context [109]. Together, these facilitate the establishment of interactive and navigation strategies to support problem-solving and to enable the learning process and the improvement of competencies [110].

Connectivism integrates the IIoT, cloud computing, and virtual reality technologies, among others, which enable connection, accessibility, and data sharing [111], as depicted in Figure 6. The engineer has to perform tasks, both training and professional, by collaboratively exchanging information in real time with machines and robots, in order to adapt to different working conditions [39]. Furthermore, connectivism seeks to create collaborative environments, connected not only between Operator 4.0 and machines and robots, but also between end customers, vendors, suppliers, and all those agents involved [112]. These strategies, in the form of instructional knowledge and subrogate instructional models, will be carried out from the cloud. 


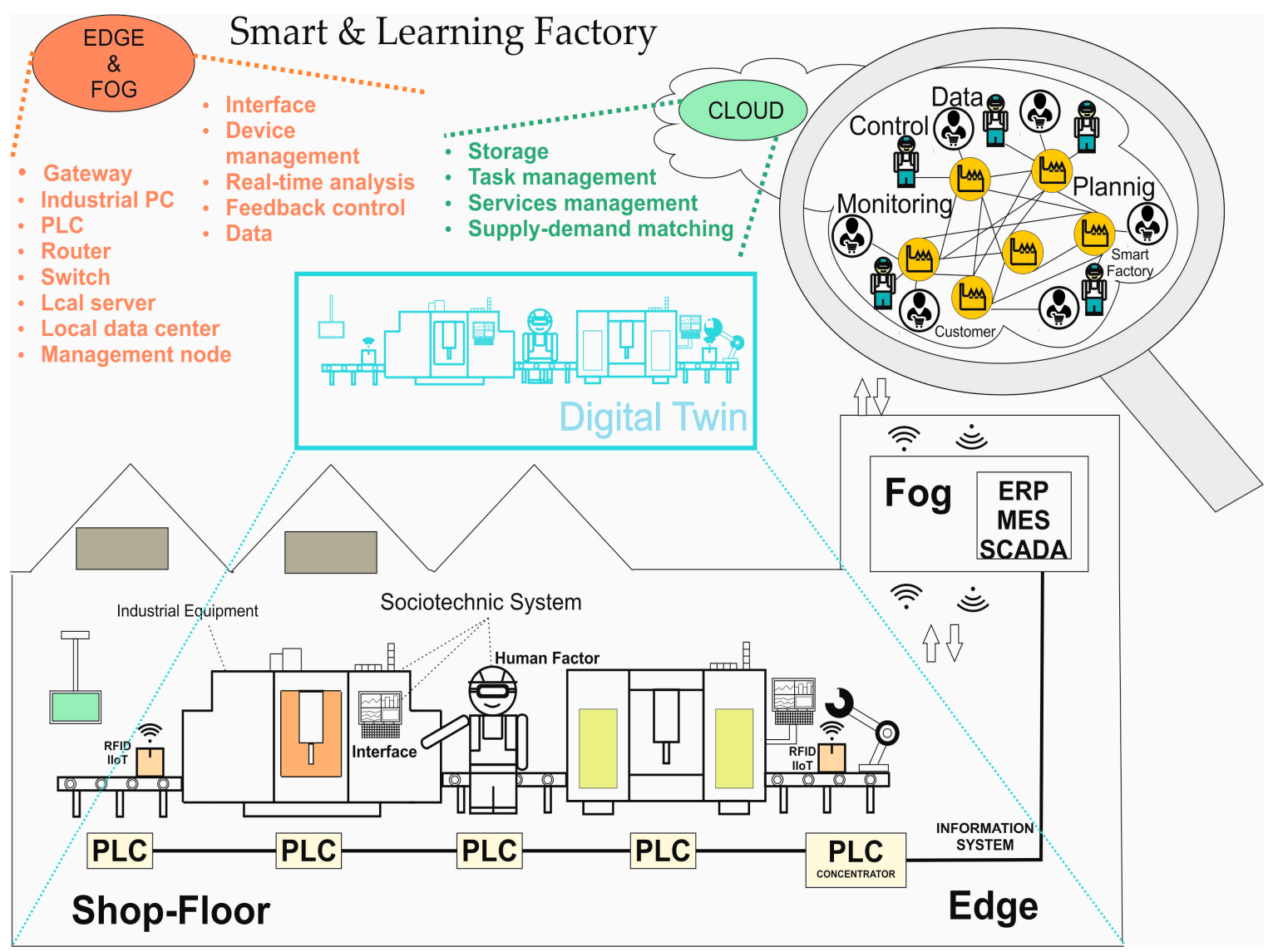

Figure 6. Connectivity in the Smart and Learning Factories.

Connectivism is based on theories of neural networks, chaos, complexity, self-organisation, and non-linear systems, from which navigation strategies are structured. Due to these influences, it integrates tools that increase, from connectivity and virtuality, the ability to facilitate interaction between the elements that shape the smart and learning factories. Connectivism has been described as the amplification of knowledge and understanding through the extension of the network, and is called the theory of knowledge for the digital age [106].

Thanks to these characteristics, the connectivist paradigm has been established as the basis for the cyber-physical socio-technical system, since it facilitates the real-time network support of cyber-physical systems as part of DfHFinI4.0, which allows constant and dynamic network workflow and training.

The navigation strategies, in conjunction with a variety of filters and amplifiers, are established in an integrated manner regarding the activity theory, which in turn, as support for activities of less granularity, constitute fractal elements [113] of top-down and button-up analysis of the SCMS for Industry 4.0, and, through the KETs, determine its greater significance by acting as lever arms.

\subsection{KETS}

Key enabling technologies have been defined as knowledge-intensive technologies associated with high-intensity research and development, rapid innovation cycles, high capital expenditure, and high-skilled employment [114]. They can also be classified as advanced manufacturing technologies, advanced materials and nanotechnologies, life-science technologies, artificial intelligence, micro/nano electronics and photonics, and security and connectivity tools.

Examples where KETS have a place include those of an organisational type (fractal, holonic, or bionic organisation), digital (cloud, big data, AR\&VR, wearables, and mobile devices) and technological type (collaborative robots, additive manufacturing, etc.) [115] Data generation, data analytics and decision-making technologies are examples of KET-artificial intelligence. 
Human-machine interfaces and cyber-physical systems provide examples of KET-security and connectivity [116,117].

Information and communication technology (ICT) and KETs challenge traditional production structures and require the search for alternative and innovative solutions to those proposed so far, through the use of disruptive activities and compentencies by Operator 4.0. This requires engineers with the ability to solve problems based on different outlooks rather than those already raised by cultural heritage. At this point, the third generation of activity theory becomes useful by allowing the transcending of established frameworks and by generating creative and innovative solutions that break with the mental structures of established systems, thereby providing solutions to the new challenges that arise.

KETs are used as variety filters and amplifiers to support DfHFinI4.0. Connectivism, together with the law of requisite variety, activity theory and KETs, help SCMS modelling, and enable real-time support and assistance for the engineer, through the design of dynamic interfaces that co-evolve according to needs considered in engineering environments 4.0, which are characterised by the digitisation and virtualisation of products and processes. This involves an impact on improvement in the acquisition and training of competencies, as well as on the affective connectivity established between human and technological factors.

\section{DfHFinI4.0 Framework}

As shown above, the technological environment promoted by Industry 4.0 determines that the tasks of Operator 4.0 are mainly focused on solving complex problems, decision-making, and the ability to adapt to new scenarios and situations in which human and technological factors work collaboratively. It is therefore important to define, design, and build SCMS in a way that allows part of the knowledge of the workers to be supported, and to respond and support, giving response and support to articulate competencies of a wider scope at the cognitive, operational, affective, and co-evolutive levels with the best working conditions. The acquisition of the competencies required in Industry 4.0 for the development of day-to-day tasks and the accumulation of know-how from the lessons learned at the workstation must also be supported. The context in which the analysis of work must be placed is within that of the value chain as an instrument of analysis of added value that incorporates the activity into products and is demanded by customers. One example of this is related to lean manufacturing systems [41], in the form of a map of the value stream, otherwise known as value stream mapping (VSM).

The analysis of the value chain of smart factories must be carried out, while considering their primary and support activities in operating conditions (professional domain), and in learning factories (academic domain). To this end, the potential of digital enablers and their projection in the integration of the human factor, machines and robots for collaborative work performance must be considered, by interacting jointly, through interfaces for both primary and support activities. The latter are elements of the SCMS that enable the interaction and navigation of Operator 4.0, not only internally, but also externally, with other socio-technical systems from other value chains, such as suppliers, distributors, customers, and plants of reverse manufacturing. This interaction takes place at a physical and virtual level, and hence the interfaces must be capable of acting as links between both physical and virtual realities. Their study is required at the level of sustainable smart manufacturing value chain design, and of associated chains of suppliers and distributors.

The productive activity in the manufacturing systems is carried out from a set of activities represented in its value chain, or VSM, based on customer value maps, which are specified downstream with various lean manufacturing tools. Subsequently, the requirements of processes, material and information flows, scheduling, tasks, equipment, operators, and their associated competencies are established [118]. As indicated before, the value chain contains primary activities and support activities that host the KETs as a means of improving their efficiency and sustainability. The process of incorporating the KETs into the activities of the value chain, focused on the human factor, requires their analysis, the potential of the KETs, the distribution of activities between those carried out by the human factor and the machines and collaborative robots, the knowledge required 
for this analysis, and strategies that support the entire manufacturing system, whose priority involves the development of strategies to empower the human factor and its affective coupling to the environment.

Based on the analysis of the added value, the analysis of the potential of the KETs and of the objective of SCMS focused on the human factor, a set of tools is proposed for the of the analysis. As illustrated in Figure 7, this analysis of the value creation activity is based on the conceptual frameworks, for the configuration of the value chain as an integrated and co-evolving SCMS to the highest degree of abstraction.

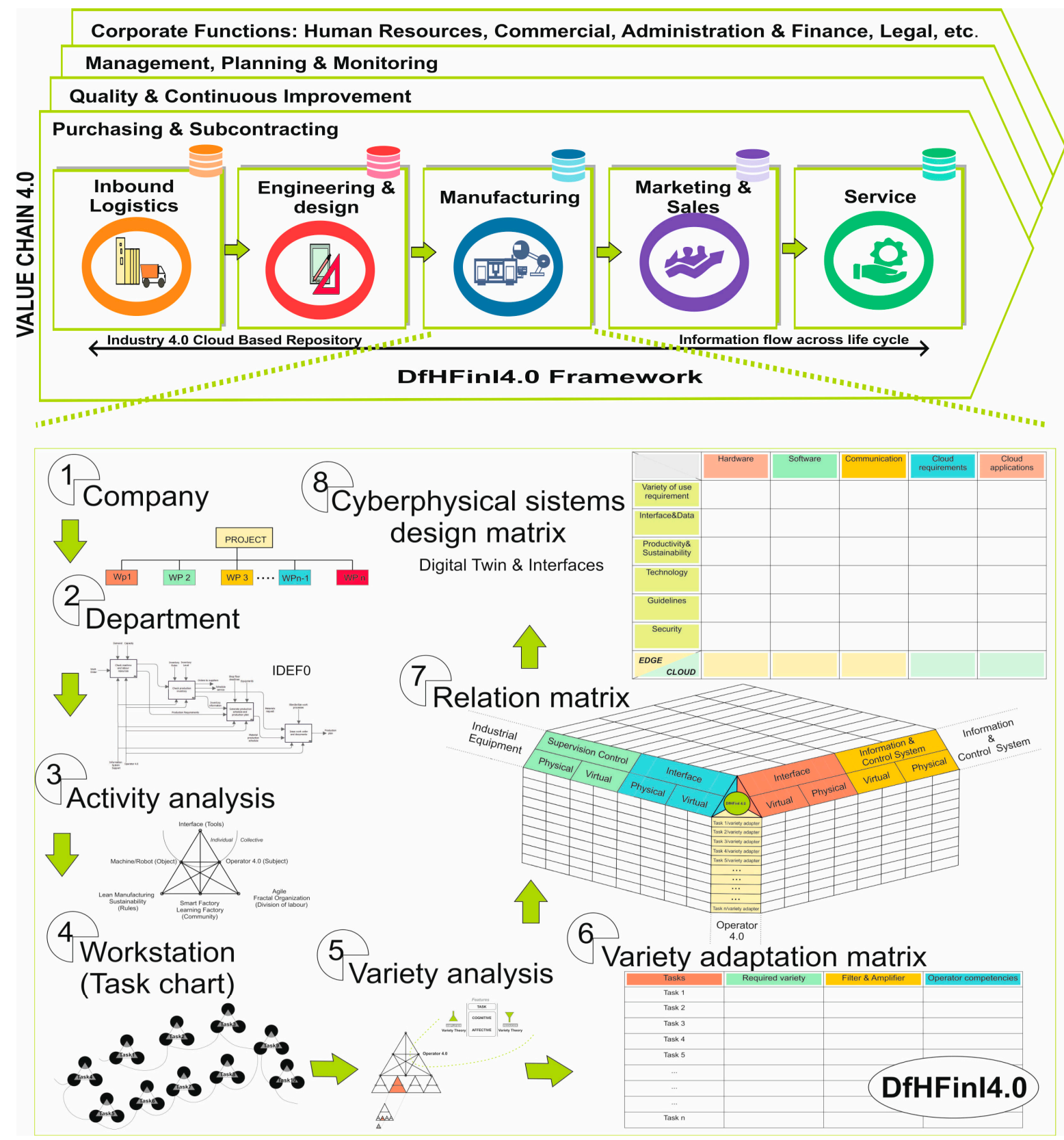

Figure 7. DfHFinI4.0 for the configuration of the integrated cyber-physical and co-evolutionary system.

The set of proposed tools are related to the activity theory model proposed in a fractal way in terms of various degrees of granularity [119], based on the analysis of the levels of company, departments, activities and workstations. Subsequently, the variety required of Operator 4.0 in workstations is characterised, as is the variety required for the successful and satisfactory development of the task, by means of the addition of the necessary filters and amplifiers through 
adaptive interfaces, and by establishing the connectivist navigation strategies that allow the operator, assisted by the competencies, to manage the lessons learned in day-to-day work. This ensures that the process, machines and robots have at least the same variety as Operator 4.0, so that the cyber-physical socio-technical system reaches stability. The modelling of the SCMS employs the duality established by the digital twin by integrating the human and technological factors through adaptive communication interfaces, thereby allowing the generation of the variety of use required for the sustainable production process, through subrogate models that are dynamically built and managed from the cloud with tools of big data and artificial intelligence, such as machine learning, classification techniques, and deep learning.

Given the potential of the digitisation of Industry 4.0, the company can establish new forms of relationships with suppliers, consumers and other value chains, by forming the global value chain through horizontal and vertical clustering with great innovative potential. This generates a horizontal integration that involves real-time cooperation between human and technological factors, as well as vertical integration between partners, suppliers, and customers, which, when brought to the field of cyber-physical systems, can be developed in a fractal way in easily replicable structures, throughout the DfHFinI4.0 framework that is proposed for the value chain of the company.

In the framework developed in this paper, the workflow is analysed through activity theory, and forms an activity system that produces and develops actions based on said theory, by breaking it down into elements at the individual level and elements at the collective level, whose explicit and implicit knowledge can be ascertained, modelled and divided between technology and the human factor. The contradictions that occur between the elements of the activity system appear once the forces that drive creativity and innovation within the smart and learning factories are resolved. This study of provoked interactions facilitates the modelling of the system itself, and explains the relationships that lead to the co-evolutive and affective coupling between the human and technological factors, which enables continuous improvement in the adaptive process between the two factors. This modelling results in a dynamic and multilateral flow of data associated with the information systems necessary for the adaptation of intelligent manufacturing to customer requirements.

Connectivism and the law of requisite variety enable the SCMS to be modelled, and characterize the particularity of the activity and the specific profile of the engineer or technician as the Operator 4.0 that carries out this activity, regarding experience, and cognitive and affective level, and adapts it through filters and variety amplifiers. Connectivism allows the establishment of navigation strategies and online assistance in problem-solving processes, through the information system, from subrogated models from the cloud, fog, and edge. This necessary connection is held on the semantic web that causes, shares, and connects content capable of being interpreted by all the elements of the cyber-physical socio-technical system. The information is collected through IIoT technologies that allow data sharing between smart devices that configure smart and learning factories, thereby fostering collaborative affective environments [120].

By establishing a cognitive design appropriate to the required variety through adaptive interfaces, its adaptive reconfiguration can take place based on the task specification and the competency model of Operator 4.0 [100]. In order to make this possible, variety adapters employed as either amplifiers or reducers are introduced in accordance with the requirements, so that the regulatory part has at least the same variety as the regulated subsystem, and the SCMS can therefore achieve stability. The design and assembly of the system, within the fractalized context of the company [121], is made up of the tasks carried out by Operator 4.0, the equipment with which it interacts, and the associated information system.

\section{Case Study: DfHFinI4.0 in PERA 4.0}

Companies, and their associated manufacturing systems 4.0, are becoming increasingly complex and dynamic. In order to reduce this complexity, the management of knowledge and operational information is needed. Business architectures, such as PERA, GERAM, and CIMOSA, have hitherto been used, while more recently, different architectures have been proposed for 
Industry 4.0, such as Holonic, RAMI 4.0, IIRA, SME, and IVI [122-124], which correspond to the different ways of implementing the informational requirements of primary activities and support the smart and sustainable value chain. Among the proposed architectures, PERA is formed by the ecosystem of business entities [125], as shown in Figure 8, in which this methodology, which constitutes its life cycle engineering, can be implemented for each of its entities.

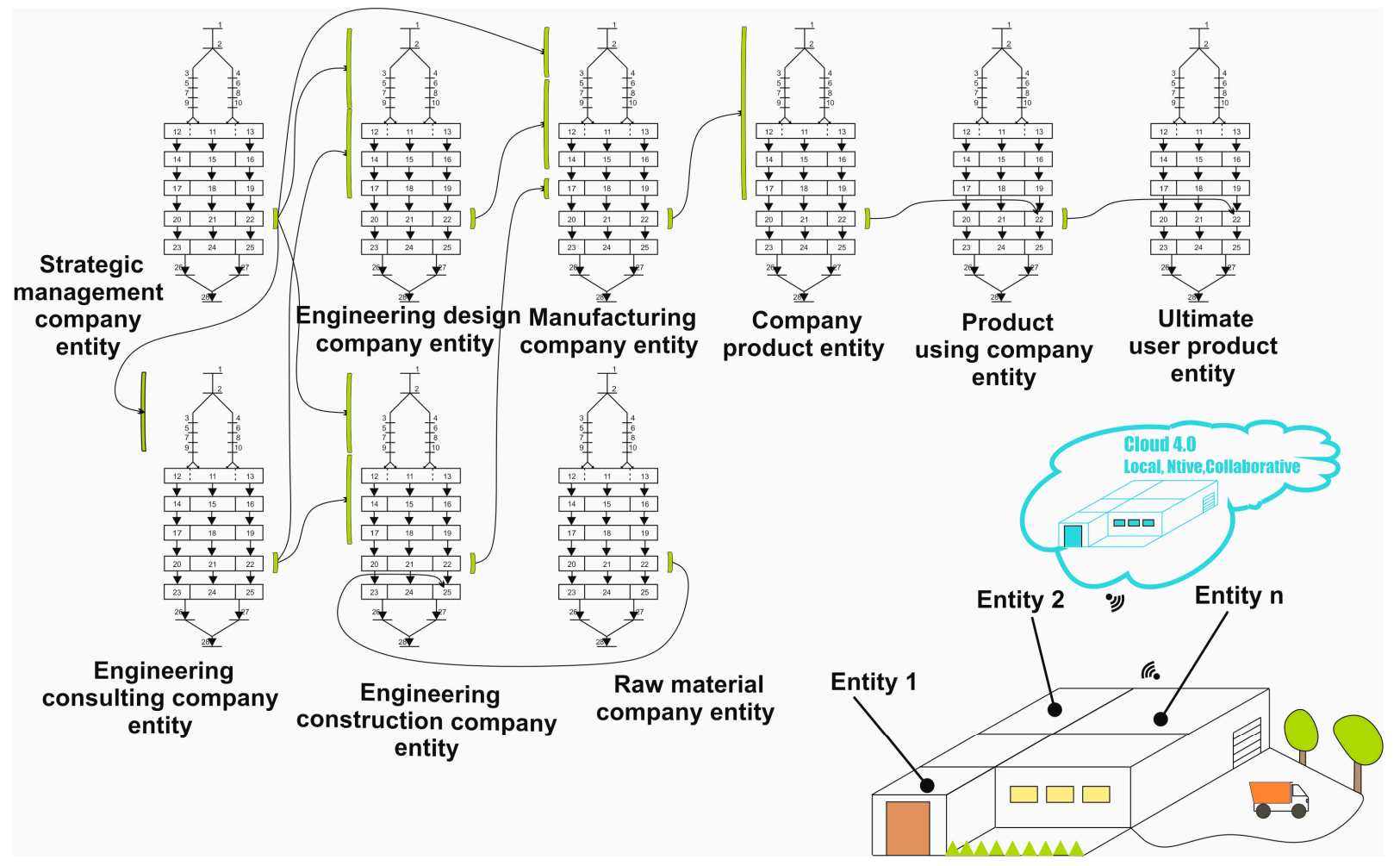

Figure 8. Entities and processes for the company in Purdue Enterprise Reference Architecture

(PERA) 4.0 architecture.

From among its characteristics, it is worth mentioning its orientation to the life cycle of the entities that make up the architecture, and considering the interaction and interfaces between technology and the human factors within its methodology. Li and Williams [126] highlighted the importance of considering good design in the communication interfaces between the diagrams that constitute the PERA model, in order to guarantee the correct exchange of information and the integration of the company, both vertically and horizontally. These characteristics determine that PERA constitutes a model of reference architecture and methodology on which to integrate the DfHFinI4.0 framework proposed under a cyber-physical conception of the entities contained therein, which evolves towards PERA 4.0. This enables research questions to be answered in life cycle engineering 4.0 formulated by Romero et al. [11], which establishes the need for the reference architecture to focus on the human factor.

The basic methodology of a PERA entity is illustrated in Figure 9. In the following, manufacturing PERA entity 3 of the architecture is employed, on which it is illustrated how the DFHinI4.0 framework proposed should be integrated together with the associated tools, which enable the cyber-physical manufacturing systems to be conceived based on the human factor. 


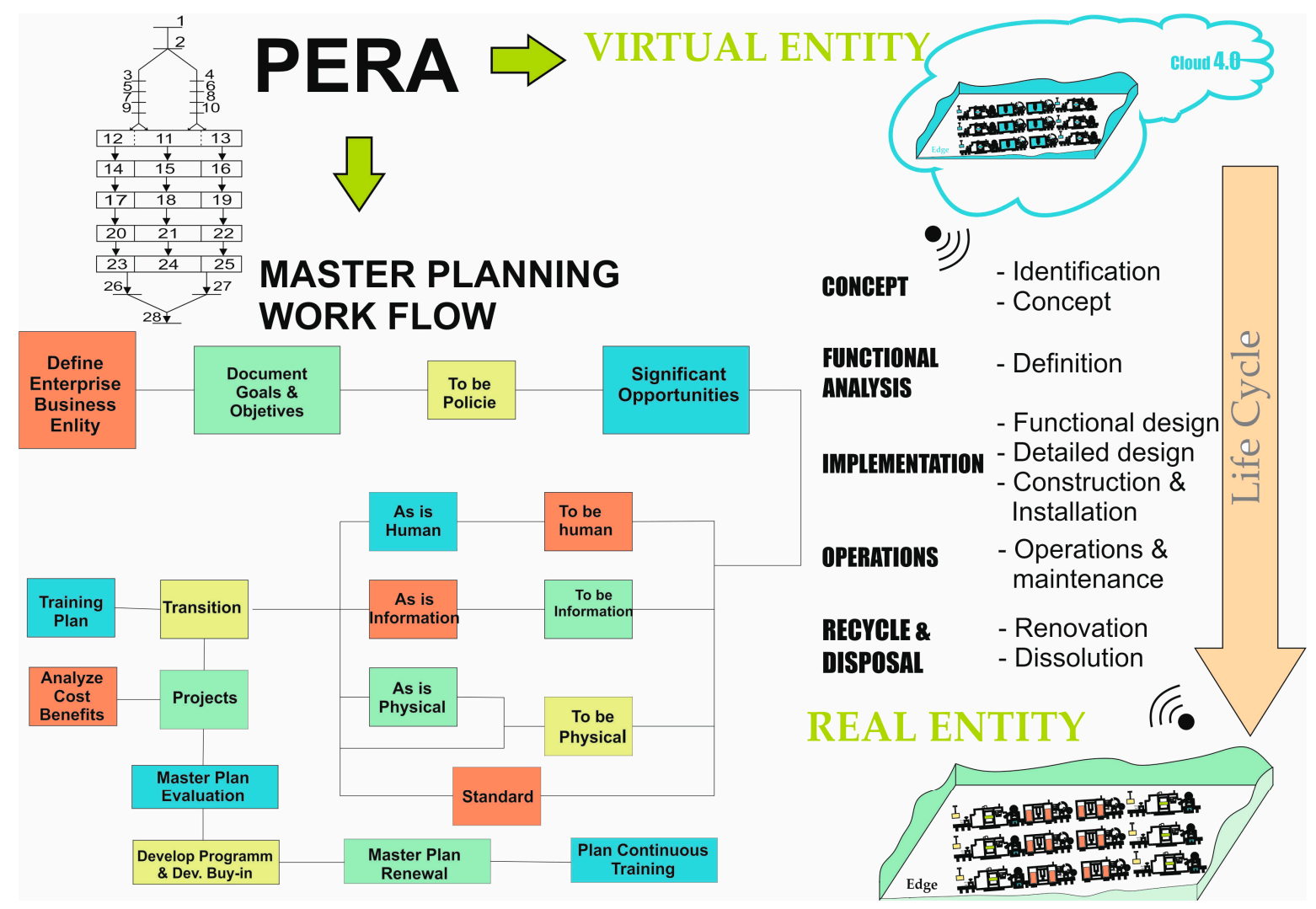

Figure 9. Basic methodology of a PERA 4.0 entity.

As indicated, PERA [127], in its methodological aspect as life cycle engineering, establishes the various regions, phases, and layers, into which the entities that constitute the company can be decomposed throughout its life cycle, while taking into account that the production equipment, the human factor, and the information and control system are involved in each element. Three separate elements are established in the design and implementation for entity three of PERA that correspond to the manufacturing system:

- The architecture of the information system.

- Human and organisational architecture.

- The architecture of the manufacturing team.

Certain vertical lines of great significance for the integration of Operator 4.0 can be observed among these elements, within which the DfHFinI4.0 framework is integrated:

- The line related to automation the PERA diagram is limited, since many tasks and functions require human innovation.

- The line related to human factors is limited by human competencies.

- The extent of the automation line represents the actual degree of automation carried out, and defines the boundaries between the three elements.

As depicted in Figure 9, the PERA methodology, in its initial proposal, contemplated the human factor, the technology, and the interfaces for their operation on industrial equipment and the information system, hitherto with no set of tools derived from conceptual frameworks of other areas of research that would allow the integration and empowerment of the human factor into digital transformation processes characterised by the connectivity and smartisation of technology.

In the proposal regarding PERA 4.0, which integrates the human factor into SCMS, as illustrated in Figure 10, the aforementioned elements are maintained. The elements and tools belonging to the DFHinI4.0 framework are incorporated into the design of socio-technical systems for the integration of the human factor, the industrial equipment, and the information and control system, thereby giving rise to two types of interfaces. In the same model, Operator 4.0 is configured 
as one more cyber-physical system, whose subrogate model obtained in the cloud will serve to adapt the interfaces and technology of the occupational environment to the operator positioned at the workstation.

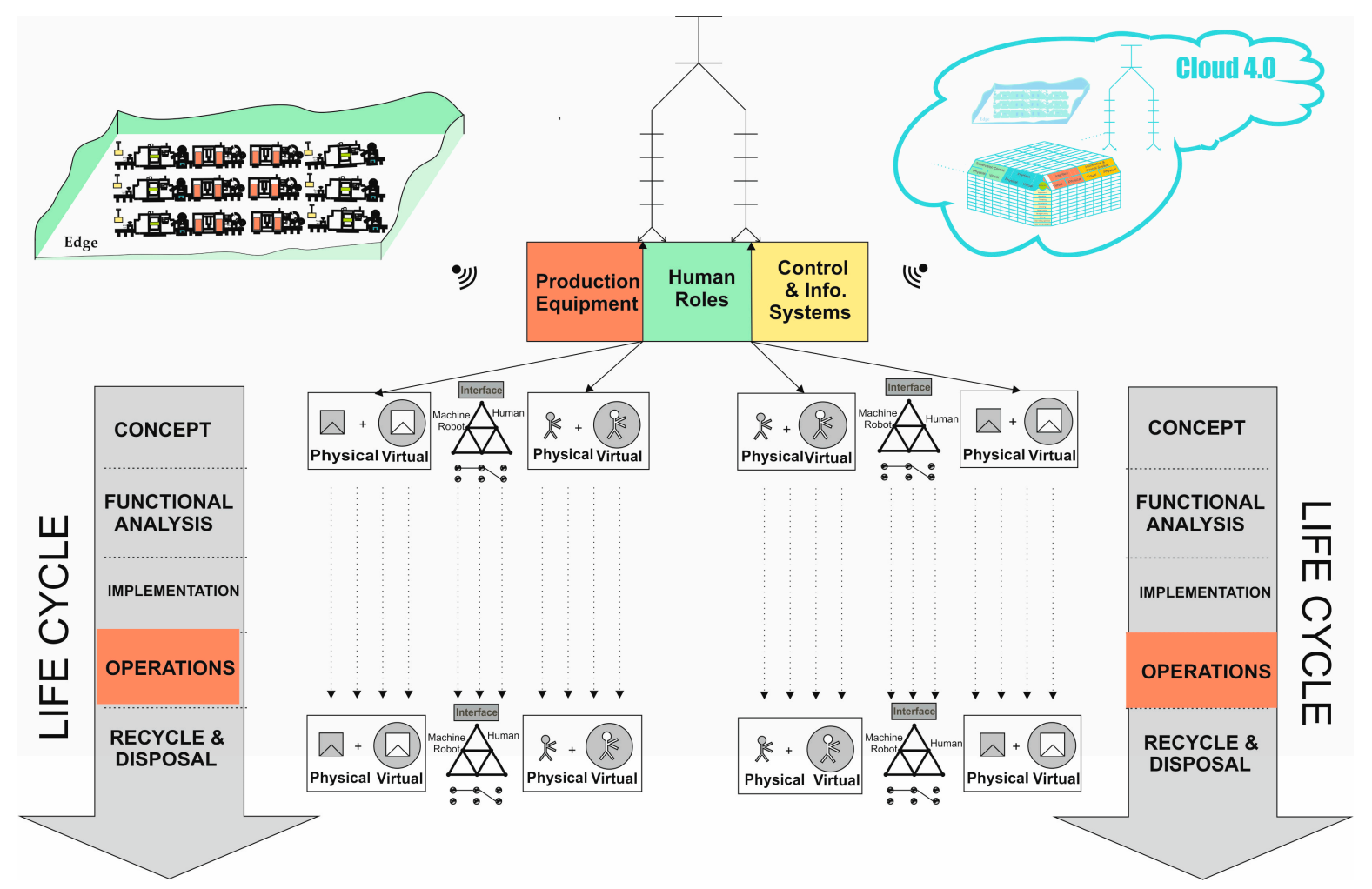

Figure 10. Integrating DfHFinI4.0 in PERA 4.0 operations phase.

The evolution of the PERA model of manufacturing entity three (analogously for the rest of the PERA entities) towards a PERA 4.0 entity three as a cyber-physical system under the possibilities of KETs, determines that the hierarchical architecture of the control system (analogous to ISA-85 and ISA-99) associated with manufacturing devices has been modified by distributed intelligent cyber-physical systems architecture, with real-time connectivity for monitoring and control in the edge and cloud. For this reason, the engineering or re-engineering of PERA towards PERA 4.0 architecture not only implies the integration and empowerment of the human factor with the DFHinI4 framework proposed, but also indicates the transformation of the hierarchical architecture, initially proposed under the PERA methodology of entity three, into a distributed architecture of cyber-physical systems based on micro-services under the PERA 4.0 methodology.

Entity three of the PERA manufacturing systems has established certain levels, characteristics and interrelations [128], which include:

- Level 0: Process. In this level, the real physical processes are defined by means of sensors, actuators, and other devices of the manufacturing process, and perform the functions of the automation and industrial control system for the measurement of the variables of the machines and the control of the process outputs. The devices communicate with each other, with the operator, and with top-level control devices.

- Level 1: Basic control. This level employs programmable automation controllers (PAC), which control and manipulate the manufacturing process, and act according to the feedback offered by the level-0 devices. The operator programs, configures, and manages these devices from the workstation through the human machine interface (HMI). In turn, the PACs (which for discrete manufacturing are called PLCs, and for process manufacturing are more specifically called DCSs) communicate with the specific information and control elements of levels 2 and 3, and also with other PACs. 
- Level 2: Supervision control area. At this level, the supervision of the execution time and the operation of an area of the production facility are carried out using HMI, alert systems, batch-processing management systems, and the control of workstations. This level 2 communicates with PACs of level 1 and shares data with business systems and the applications of levels 4 and 5 .

- Level 3: Manufacturing and control operations. This represents the highest level of the industrial automation and control system. This level includes the functions involved in managing workflows.

- Level 4: Business planning and site logistics. This level includes programming systems, material flow applications, manufacturing execution systems (MES), and information technology services (ITS).

- Level 5: Company. Residing at this level are the business resource management services, company-company through ERP and company-client through CRM for the PLM product, and BIM for the facility.

Figure 11 shows the incorporation of the DFHinI4.0 framework in a fractalized way, in the design and development of the various entities of the PERA 4.0 architecture for all the phases of the life cycle engineering that integrates the PERA methodology. This framework enables interactions between the human and technological factors to be modelled, and establishes their integration and development dynamically for each of the stages of the life cycle. This situation, together with the conception of the manufacturing entity as an intelligent and distributed cyber-physical system, gives rise to PERA 4.0 as a distributed system and life cycle engineering 4.0 methodology, which empowers the human factor, as shown.

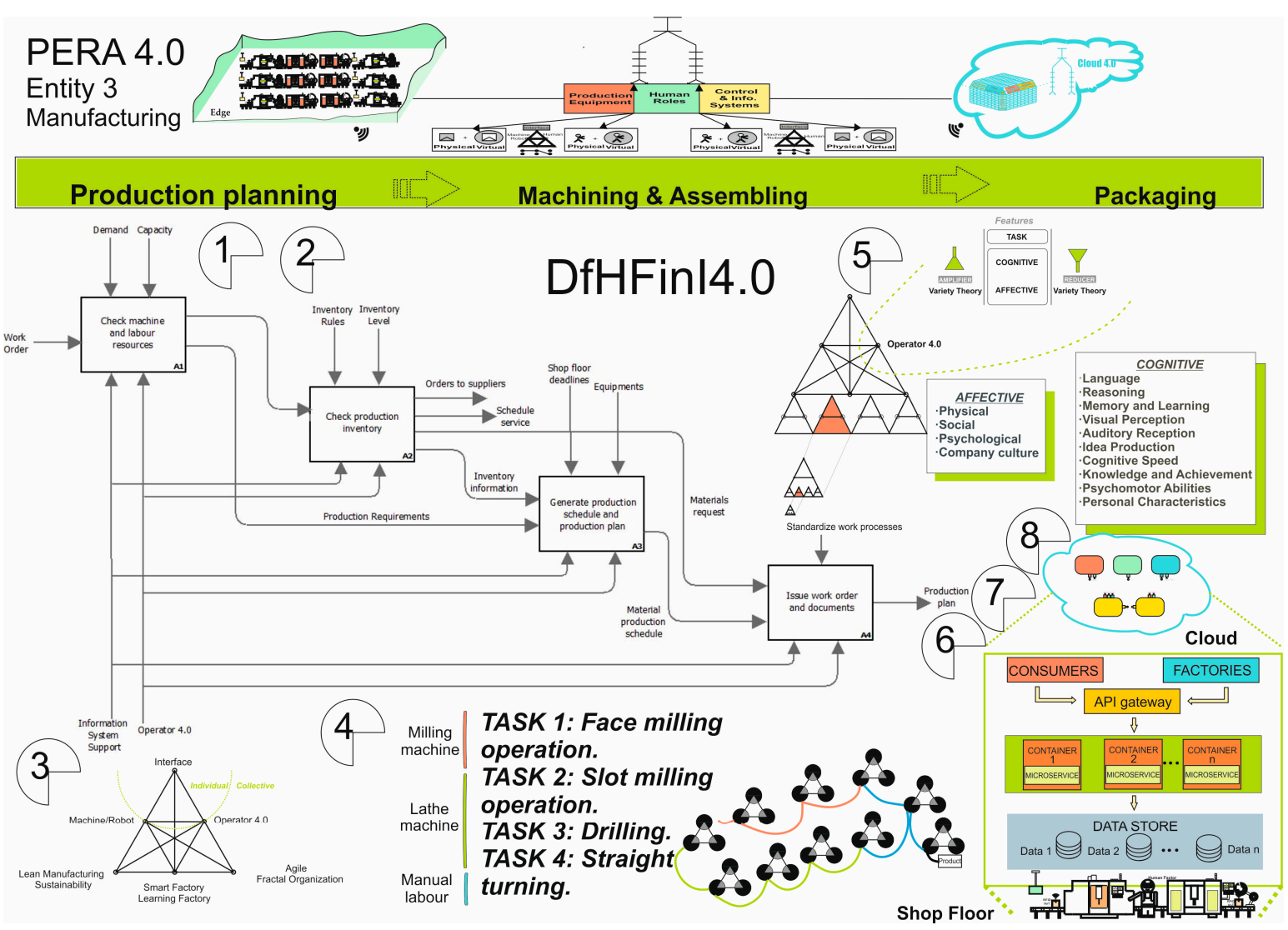

Figure 11. Application of the DfHFinI4.0 framework to the design and development process of entity three of PERA in the manufacturing system.

For the management of the reconfiguration of the technological occupational environment, accordance with the characteristics and competence of the Operators 4.0, who can be interacting 
with the system at any given moment, it is proposed that the operator, as a cyber-physical system, possess a cloud model of its operational singularity. This model refers to experience, knowledge, capabilities, competences, and other characteristics, which, as parameters of a subrogated model, allow the technology to be adapted, as represented in Figure 11. To this end, the operator model is sent from the cloud to the edge when necessary. The operators are sensed and assisted by the KETs, which transmit the data of the operators to the cloud to configure a more refined subrogate model, that in turn, is sent to the edge, which leads to the adaptation of the interface and technologies to Operator 4.0, thereby empowering this operator and enabling affective coupling. Big data techniques, learning machines, and deep learning will be employed in the preparation of the subrogate model.

Under the PERA 4.0 approach of manufacturing system entity three, the hierarchical levels of control established by PERA must be embedded in a distributed system of its cyber-physical entities, with intelligence and local connectivity in the edge, and global intelligence and connectivity in the cloud through IIoT. Figure 12 presents a schematic of the way in which the information system of the manufacturing system can evolve for its integration into any of the distributed architectures of Industry 4.0. In our proposal, we opted for holonic architecture [122], and for the modelling of the different holons, the Arrowhead methodology is proposed, both locally and globally [129]. This approach can be carried out by using blockchain technology, through the open-source container orchestration and choreography software tool called Kubernetes, and the creation of container images by using Docker [130].

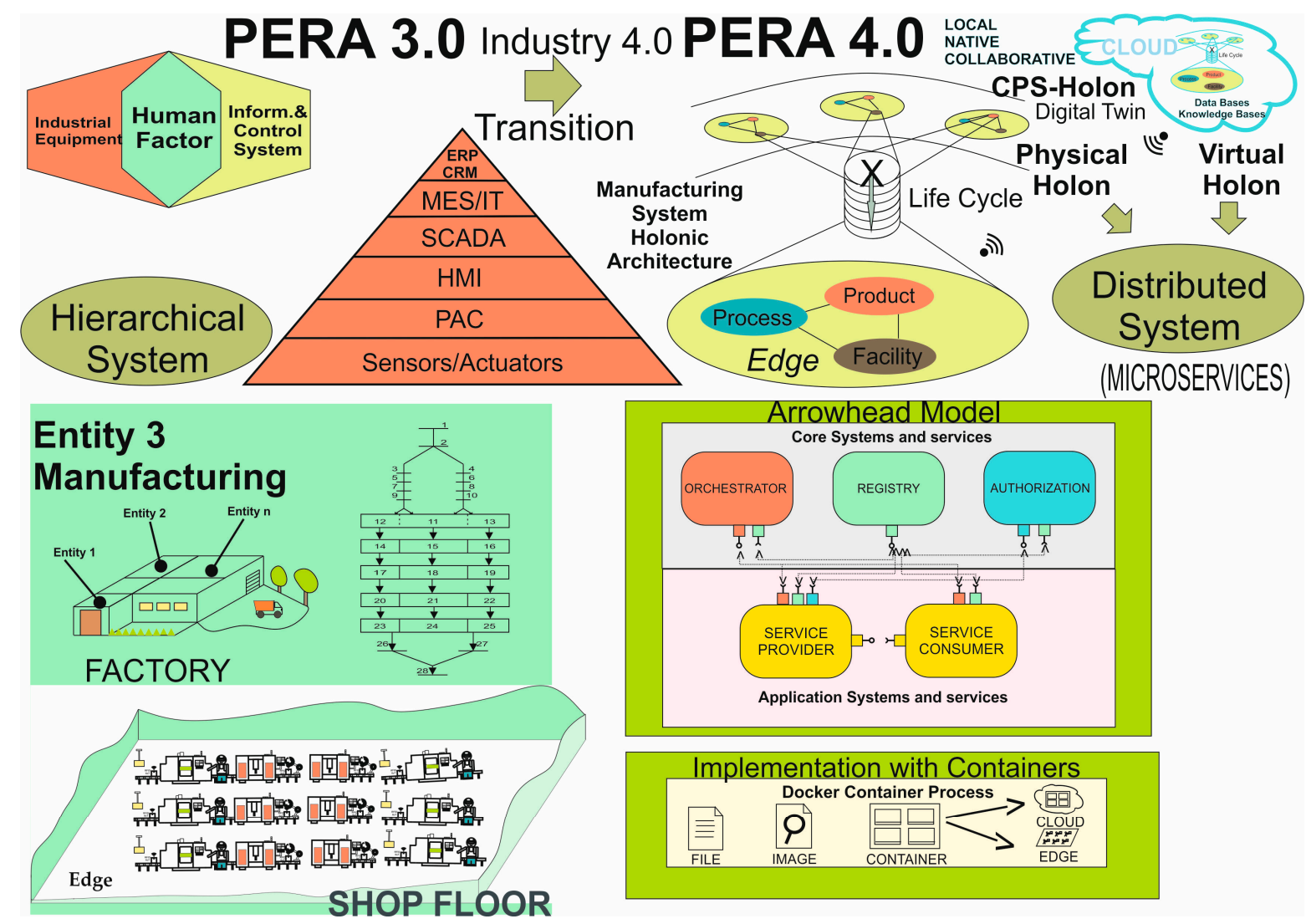

Figure 12. Evolution of the PERA control architecture to the PERA 4.0 architecture.

\section{Discussion}

This work proposes a framework (DfHfinI4.0) for the conception of manufacturing systems as cyber-physical socio-technical systems, from the perspective of Life Cycle Engineering 4.0. In this framework, the symbiotic conception of linked processes, teams, and people is established through adaptive interfaces that enable the operation, growth, and development of Operator 4.0. The proposed model enables the processes, their activities, and tasks to be studied, in order to search for 
potential synergies through its reconfiguration and customisation in accordance with Operator 4.0, thereby providing the online support required.

The most significant limitation of the proposed model involves the necessary sensitisation of the engineering teams in the socio-cognitive approach to the conception of socio-technical systems.

Regarding the relationship of the results obtained from the proposed DfHfinI4.0 model and from the application of the case study to the PERA 4.0 architecture, it should be borne in mind that it is impossible to establish a comparative relationship of results, due to the current lack of investigations regarding Operator 4.0 with the proposed scope and reference architectures that support techniques for the conception synergy of socio-technical systems.

\section{Conclusions}

The objectives of this work include: the identification of the degree of incorporation of the human factor in the different areas of digital and technological transformation of Industry 4.0, and the formulation of a model that the value of this factor in engineering and re-engineering processes to be evaluated, while taking into account Industry 4.0, which incorporates knowledge from other areas of research. A proposal is made for the application of the DfHFinI4.0 framework to one of the most significant reference architectures and methodologies, with the incorporation of the characteristics of Industry 4.0 as a reference. All of the above constitutes a solid proposal that enables the development of a framework for SCMS Life Cycle 4.0 Engineering.

With regard to the first objective, it should be considered that the human factor has not received the same attention as technology has in digital transformation processes. As a consequence of the previous consideration, it is necessary to investigate proposals that constitute an empowerment of the situation in which, in most cases, the human factor has been installed in digital transformation processes, thereby wasting human talent and its wider scope with the hybridisation of the technology.

In relation to the identification and selection of conceptual frameworks on which to build a SCMS design methodology focused on the human factor, after a bibliographic analysis and due to the importance of interfaces and navigation processes in Industry 4.0, we have opted for the conceptual fields of Vigotsky's activity theory (AT), Ashby's law of required variety (LRV), and the connectivist paradigm (CP). The latter two methologies are integrated into the activity theory model, thereby establishing an integrated formalism for the distribution of work, competencies, and analysis of the required variety, as well as establishing the filters and amplifiers of a variety of navigation strategies of Operators 4.0.

The proposed framework is called DFHinI4.0, within which AT, LRV, and CP are articulated in eight integrated steps that lead to the configuration of SCMS, focused on the human factor. This framework enables affective and timeless occupational experiences in the development of work, through the interfaces of hybridised equipment, both in its physical and virtual dimensions in the cloud. This framework is conceived with a degree of generality that allows its fractal implementation at the various levels of granularity and phases of Life Cycle Engineering 4.0.

Finally, both the DFHinI4.0 framework and the perspective of Life Cycle Engineering 4.0 are implemented in PERA, thereby configuring it as PERA 4.0 in the case of entity 3 of SCMS. A proposal is made for a distributed approach to hierarchical control architectures over PERA manufacturing systems, by means of a holonic architecture based on the model of connectors that considers micro-services for their development with blockchain technology. In this case, Section 5 enables the proposed framework to be validated, as shown by the improvement in dimension 1 related to the modelling and simulation of SCMS, which appear in subsection 2.5 Research Gap.

Author Contributions: Conceptualisation, methodology, investigation and writing-original draft, S.S.-F.M. and F.A.-G; writing-review and editing, S.S.-F.M., F.A.-G., J.S.-G, and M.J.A.-G. All authors have read and agreed to the published version of the manuscript.

Funding: This research has received no external funding.

Conflicts of Interest: The authors declare there to be no conflict of interest. 


\section{References}

1. Trstenjak, M.; Cosic, P. Process Planning in Industry 4.0 Environment. Procedia Manuf. 2017, 11, doi:10.1016/j.promfg.2017.07.303.

2. Bennett, N.; Lemoine, G.J. What a difference a word makes: Understanding threats to performance in a VUCA world. Bus. Horiz. 2014, 57, 311-317, doi:10.1016/j.bushor.2014.01.001.

3. Tao, F.; Cheng, Y.; Xu, L. Da; Zhang, L.; Li, B.H. CCIoT-CMfg: Cloud computing and internet of things-based cloud manufacturing service system. IEEE Trans. Ind. Informatics 2014, 10, 1435-1442.

4. Pandit, D.; Joshi, M.P.; Sahay, A.; Gupta, R.K. Disruptive innovation and dynamic capabilities in emerging economies: Evidence from the Indian automotive sector. Technol. Forecast. Soc. Change 2018, 129, 323-329, doi:10.1016/j.techfore.2017.09.035.

5. Suárez Fernández-Miranda, S.; Marcos, M.; Peralta, M.E.; Aguayo, F. The challenge of integrating Industry 4.0 in the degree of Mechanical Engineering. Procedia Manuf. 2017, 13, doi:10.1016/j.promfg.2017.09.039.

6. Yan, H.; Wan, J.; Zhang, C.; Tang, S.; Hua, Q.; Wang, Z. Industrial Big Data Analytics for Prediction of Remaining Useful Life Based on Deep Learning. IEEE Access 2018, 6, 17190-17197.

7. Plumanns, L.; Printz, S.; Vossen, R.; Jeschke, S. Strategic Management of Personnel Development in the Industry 4.0. In Proceedings of the 14th International Conference on Intellectual Capital, Knowledge Management \& Organisational Learning: ICICKM 2017, Hong Kong, China, 7-8 December 2017; Hong Kong, China, 2017; pp. 179-186.

8. Tirabeni, L.; De Bernardi, P.; Forliano, C.; Franco, M. How Can Organisations and Business Models Lead to a More Sustainable Society? A Framework from a Systematic Review of the Industry 4.0. Sustainability 2019, 11, 23, doi:10.3390/su11226363.

9. Tran, N.-H.; Park, H.-S.; Nguyen, Q.-V.; Hoang, T.-D. Development of a Smart Cyber-Physical Manufacturing System in the Industry 4.0 Context. Appl. Sci. 2019, 9, 24, doi:10.3390/app9163325.

10. Vrchota, J.; Pech, M. Readiness of Enterprises in Czech Republic to Implement Industry 4.0: Index of Industry 4.0. Appl. Sci. 2019, 9, 25, doi:10.3390/app9245405.

11. Romero, D.; Stahre, J.; Wuest, T.; Noran, O.; Bernus, P.; Fast-Berglund, Å.; Gorecky, D. Towards an Operator 4.0 Typology: A Human-Centric Perspective on the Fourth Industrial Revolution Technologies. In Proceedings of the 46th International Conference on Computers \& Industrial Engineering, Tianjin, China, 29-31 October 2016; pp. 1-11.

12. Romero, D.; Bernus, P.; Noran, O.; Stahre, J.; Berglund, Å.F. The operator 4.0: Human cyber-physical systems \&amp; adaptive automation towards human-automation symbiosis work systems. In Proceedings of the. IFIP International Conference on Advances in Production Management Systems, Iguassu Falls, Brazil, 3-7 September 2016; Springer LLC: New York, NY, USA 2016; Volume 488, pp. 677-686, doi:10.1007/978-3-319-51133-7_80.

13. Taylor, M.P.; Boxall, P.; Chen, J.J.J.; Xu, X.; Liew, A.; Adenijib, A. Operator 4.0 or Maker 1.0? Exploring the implications of Industrie 4.0 for innovation, safety and quality of work in small economies and enterprises. Comput. Ind. Eng. 2020, 139, 5, doi:10.1016/j.cie.2018.10.047.

14. Enke, J.; Glass, R.; Kreß, A.; Hambach, J.; Tisch, M.; Metternich, J. Industrie 4.0-Competencies for a modem production system A curriculum for Learning Factories. Procedia Manuf. 2018, 23, 267-272.

15. Emmanouilidis, Ch.; Pistofidis, P.; Bertoncelj, L.; Katsouros, V.; Fournaris, A.; Koulamas, Ch.; Ruiz-Carcel, C. Enabling the human in the loop: Linked data and knowledge in industrial cyber-physical systems. Annu. Rev. Control. 2019, 47, 249-265, doi:10.1016/j.arcontrol.2019.03.004.

16. Zakoldaev, D.A.; Gurjanov, A.V.; Shukalov, A.V.; Zharinov, I.O. Implementation of H2M technology and augmented reality for operation of cyber-physical production of the Industry 4.0. J. Phys. Conf. Ser. 2019, 1353, 5, doi:10.1088/1742-6596/1353/1/012142.

17. Segura, A.; Diez, H.V.; Barandiaran, I.; Arbelaiz, A.; Álvarez, H..; Simões, B.; Posada, J.; García-Alonso, A.; Ugarte, R. Visual computing technologies to support the Operator 4.0. Comput. Ind. Eng. 2020, 139, 9 , doi:10.1016/j.cie.2018.11.060.

18. Tamás Ruppert, Szilárd Jaskó, Tibor Holczinger, J.A. Enabling Technologies for Operator 4.0: A Survey. Appl. Sci. 2018, 8, 19, doi:10.3390/app8091650.

19. Zolotová, I.; Papcun, P.; Kajáti, E.; Miškuf, M.; Mocnej, J. Smart and cognitive solutions for Operator 4.0: Laboratory H-CPPS case studies. Comput. Ind. Eng. 2020, 139, 15, doi:10.1016/j.cie.2018.10.032.

20. Fantini, P.; Pinzone, M.; Taisch, M. Placing the operator at the centre of Industry 4.0 design: Modelling 
and assessing human activities within cyber-physical systems. Comput. Ind. Eng. 2020, 139, 11, doi:10.1016/j.cie.2018.01.025.

21. Peruzzinia, M.; Fabio Grandia, M.P. Exploring the potential of Operator 4.0 interface and monitoring. Comput. Ind. Eng. 2020, 139, 19, doi:10.1016/j.cie.2018.12.047.

22. Umeda, Y.; Takata, S.; Kimura, F.; Tomiyama, T.; Sutherland, J.W.; Kara, S.; Herrmann, C.; Duflou, J.R. Toward integrated product and process life cycle planning-An environmental perspective. CIRP Ann. Manuf. Technol. 2012, 61, 681-702, doi:10.1016/j.cirp.2012.05.004.

23. Yan, P.; Zhou, M.C. A life cycle engineering approach to development of flexible manufacturing systems. IEEE Int. Conf. Robot. Autom. 2003, 19, 465-473, doi:10.1109/TRA.2003.810583.

24. Wanyama, W.; Ertas, A.; Zhang, H.C.; Ekwaro-Osire, S. Life-cycle engineering: Issues, tools and research. Int. J. Comput. Integr. Manuf. 2003, 16, 307-316, doi:10.1080/0951192031000089255.

25. Würtz, G.; Kölmel, B. Integrated Engineering-A SME-Suitable Model for Business and Information Systems Engineering (BISE) towards the Smart Factory. IFIP Advances in Information and Communication Technology. 2012, 380, pp. 494-502, https://doi.org/10.1007/978-3-642-32775-9_50.

26. Mayer, P. Guidelines for writing a review article. Zurich-Basel Plant Sci. Cent. 2009, 82, 1-10.

27. Coelho, D. A growing concept of ergonomics including pleasure. comfort and cognitive engineering: An engineering design perspective. Ph.D. Thesis, The University of Beira Interior, Covilhã, Portugal, 2002.

28. Galindo-Rueda, F.; Verger, F. OECD taxonomy of economic activities based on R\&amp;D intensity. OECD Publishing, Paris. OECD Sci. Technol. Ind. Work. Pap. 2016, 4, doi:10.1787/5jlv73sqqp8r-en.

29. National Science Board, N.S.F. Science and Engineering Indicators 2020: The State of U.S. Science and Engineering; NSB-2020-1: Alexandria, VA, USA, 2020.

30. Lee, J.; Bagheri, B.; Kao, H.A. A Cyber-Physical Systems architecture for Industry 4.0-based manufacturing systems. Manuf. Lett. 2015, doi:10.1016/j.mfglet.2014.12.001.

31. Zhou, J.; Zhou, Y.; Wang, B.; Zang, J. Human-Cyber-Physical Systems (HCPSs) in the Context of New-Generation Intelligent Manufacturing. Engineering 2019, 5, 624-636, doi:10.1016/j.eng.2019.07.015.

32. Rødseth, H.; Eleftheriadis, R.; Lodgaard, E.; Fordal, J.M. Operator 4.0-Emerging job categories in manufacturing. Lect. Notes Electr. Eng. 2019, 484, 114-121, doi:10.1007/978-981-13-2375-1_16.

33. Krugh, M.; McGee, E.; McGee, S.; Mears, L.; Ivanco, A.; Podd, K.C.; Watkins, B. Measurement of Operator-machine Interaction on a Chaku-chaku Assembly Line. Procedia Manuf. 2017, doi:10.1016/j.promfg.2017.07.039.

34. Zamora, M.; Caldwell, E.; Garcia-Rodriguez, J.; Azorin-Lopez, J.; Cazorla, M. Machine Learning Improves Human-Robot Interaction in Productive Environments: A Review; In Proceedings of the International Work-Conference on Artificial Neural Networks, IWANN 2017, Cadiz, Spain, June 14-16, 2017; Proc. Lect. Notes Comput. Sci. (including Subser. Lect. Notes 812 Artif. Intell. Lect. Notes Bioinformatics); Springer Verlag: Berlin, Germany, 2017; 10306, pp. 283-293.

35. Frynas, J.G.; Mol, M.J.; Mellahi, K. Management Innovation Made in China: Haier's Rendanheyi. Calif. Manag. Rev. 2018, 61, 71-93, doi:10.1177/0008125618790244.

36. Shamim, S.; Cang, S.; Yu, H.; Li, Y. Management approaches for Industry 4.0: A human resource management perspective. In Proceedings of the 2016 IEEE Congress on Evolutionary Computation (CEC), Vancouver, BC, Canada, 24-29 July 2016; pp. 5309-5316, doi:10.1109/CEC.2016.7748365.

37. Lv, Y.; Lin, D. Design an intelligent real-time operation planning system in distributed manufacturing network. Ind. Manag. Data Syst. 2017, 117, 742-753, doi:10.1108/IMDS-06-2016-0220.

38. Neuböck, T.; Schrefl, M. Modelling Knowledge about Data Analysis Processes in Manufacturing. In Proceedings of the IFAC Symposium on Information Control in Manufacturing Ottawa, ON, Canada, 11-13 May 2015; Volume 48, pp. 277-282, doi:10.1016/j.ifacol.2015.06.094.

39. Sanin, C.; Shafiq, I.; Waris, M.M.; Toro, C.; Szczerbicki, E. Manufacturing collective intelligence by the means of Decisional DNA and virtual engineering objects, process and factory. J. Intell. Fuzzy Syst. 2017, 32, 1585-1599, doi:10.3233/JIFS-169152.

40. Chen, Y.; Lee, G.M.; Shu, L.; Crespi, N. Industrial Internet of Things-based collaborative sensing intelligence: Framework and research challenges. Sensors 2016, 16, 1-19, doi:10.3390/s16020215.

41. Synnes, E.L.; Welo, T. Enhancing Integrative Capabilities through Lean Product and Process Development. Procedia CIRP 2016, 54, 221-226, doi:10.1016/j.procir.2016.05.090.

42. Küsters, D.; Praß, N.; Gloy, Y.S. Textile Learning Factory 4.0-Preparing Germany's Textile Industry for the Digital Future. Procedia Manuf. 2017, 9, 214-221, doi:10.1016/j.promfg.2017.04.035. 
43. Mehta, P.; Rao, P.; Wu, Z.D.; Jovanović, V.; Wodo, O.; Kuttolamadom, M. Smart manufacturing: State-of-The-Art reviewin context of conventional \& modern manufacturing. In Proceedings of the ASME 2018 13th International Manufacturing Science and Engineering Conference 18-22 June 2018 College Station, TX, USA, 2018; Volume 3, pp. 1-21, doi:10.1115/MSEC2018-6658.

44. Büth, L.; Juraschek, M.; Posselt, G.; Herrmann, C. Supporting SMEs towards adopting mixed reality A training concept to bring the reality-virtuality continuum into application. In Proceedings of the 2018 IEEE 16th International Conference on Industrial Informatics, Porto, Portugal, 18-20 July, 2018; pp. 544-549, doi:10.1109/INDIN.2018.8471990.

45. Govindarajan, U.H.; Trappey, A.J.C.; Trappey, C.V. Immersive Technology for Human-Centric Cyberphysical Systems in Complex ManufacturingProcesses: A Comprehensive Overview of the Global Patent Profile Using Collective Intelligence. Complexity 2018, 17, doi:10.1155/2018/4283634.

46. Cimini, C.; Pinto, R.; Cavalieri, S. The business transformation towards smartmanufacturing: A literature overview about reference models and research agenda. IFAC-PapersOnLine 2017, 50, 14952-14957, doi:10.1016/j.ifacol.2017.08.2548.

47. Stark, R.; Kind, S.; Neumeyer, S. Innovations in digital modelling for next generation manufacturing system design. CIRP Ann-Manuf. Technol. 2017, 66, 169-172, doi:10.1016/j.cirp.2017.04.045.

48. Cheng, H.; Xue, L.; Wang, P.; Zeng, P.; Yu, H. Ontology-Based Web Service Integration for FlexibleManufacturing Systems. In Proceedings of the 2017 IEEE 15th International Conference on Industrial Informatics, Emden, Germany, 24-26 July 2017, pp. 351-356, doi:10.1109/INDIN.2017.8104797.

49. Klöber-Koch, J.; Pielmeier, J.; Grimm, S.; Brandt, M.M.; Schneider, M.; Reinhart, G. Knowledge-Based Decision Making in a Cyber-Physical Production Scenario. Procedia Manuf. 2017, 9, 167-174, doi:10.1016/j.promfg.2017.04.014.

50. Qi, Q.; Tao, F. A Smart Manufacturing Service System Based on Edge Computing, Fog, Computing, and Cloud Computing. IEEE Access 2019, 7, 86769-86777.

51. Qu, S.; Wang, J.; Govil, S.; Leckie, J.O. Optimized Adaptive Scheduling of a Manufacturing Process System with Multi-Skill Workforce and Multiple Machine Types: An Ontology-Based, Multi-Agent Reinforcement Learning Approach. Procedia CIRP 2016, 57, 55-60, doi:10.1016/j.procir.2016.11.011.

52. Jaensch, F.; Csiszar, A.; Scheifele, C.; Verl, A. Digital Twins of Manufacturing Systems as a Base for Machine Learning. In Proceedings of the 25th International Conference on Mechatronics and Machine Vision in Practice (M2VIP), Stuttgart, Germany, 20-22 November 2018, pp. 1-6, doi:10.1109/M2VIP.2018.8600844.

53. Mortensen, S.T.; Madsen, O. A Virtual Commissioning Learning Platform. Procedia Manuf. 2018, 23, 93-98, doi:10.1016/j.promfg.2018.03.167.

54. Kaihara, T.; Katsumura, Y.; Suginishi, Y.; Kadar, B. Simulation model study for manufacturingeffectiveness evaluation in crowdsourcedmanufacturing. CIRP Ann. Manuf. Technol. 2017, 66, 445-448, doi:10.1016/j.cirp.2017.04.094.

55. Jiang, P.; Leng, J. The Configuration of Social Manufacturing: A Social Intelligence Way Toward Service-Oriented Int. J. Manuf. Res. 2016, 12, doi:10.1504/IJMR.2017.083647.

56. Cachada, A.; Barbosa, J.; Leitão, P.; Gcraldcs, C.A.S.; Deusdado, L.; Costa, J.; Teixeira, J.; Moreira, A.H.J.; Miguel, P.; Romero, L.; et al. Maintenance 4.0: Intelligent and Predictive Maintenance System Architecture. In Proceedings of the 2018 IEEE 23rd International Conference on Emerging Technologies and Factory Automation (ETFA), Turin, Italy, 4-7 September 2018; pp. 139-146, doi:doi:10.1109/ETFA.2018.8502489.

57. Fisher,O.;Watson, N.; Porcu, L.; Baco, D.; Rigley, M.; Gomes, R.L. Cloud manufacturing as a sustainable process manufacturing route. J. Manuf. Syst. 2018, 47, 53-68, doi:10.1016/j.jmsy.2018.03.005.

58. Zhang, Y.; Ren, S.; Liu, Y.; Si, S. A big data analytics architecture for cleaner manufacturing and maintenance processes of complex products. J. Clean. Prod. 2017, doi:10.1016/j.jclepro.2016.07.123.

59. Berg, L.P., Vance, J.M. Industry use of virtual reality in product design and manufacturing: A survey. Virtual Real. 2017, 21, 1-17, doi:10.1007/s10055-016-0293-9.

60. Pai, Y.S.; Yap, H.J.; Zawiah, S.; Dawal, S.Z.; Ramesh, S.; Phoon, S.Y. Virtual Planning, Control., and Machining for a Modular-Based Automated Factory Operation in an Augmented Reality Environment. Sci. Rep. 2016, doi:10.1038/srep27380

61. Lawrence, K. Developing Leaders in a VUCA Environtment; UNC Kenan-Flagler Bussines School: Chapel Hill, NC, USA, 2013. 
62. Centea, D.; Elbestawi, M.; Singh, I.; Wanyama, T. SEPT Learning Factory Framework. In Smart Industry $\mathcal{E}$ Smart Education, Proceedings of the 15th International Conference on Remote Engineering and Virtual Instrumentation, Duesseldorf, Germany, 21-23 March 2018; Lecture Notes in Networks and Systems; Auer M., Langmann R., Eds.; Springer: Cham, Switzerland, 2019; Volume 47, doi:10.1007/978-3-319-95678-7_40.

63. Schallock, B.; Rybski, C.; Jochem, R.; Kohl, H. Learning Factory for Industry 4.0 to provide future skills beyond technical training. Procedia Manuf. 2018, 23, 27-32, doi:10.1016/j.promfg.2018.03.156.

64. Baena, F.; Guarin, A.; Mora, J.; Sauza, J.; Retat, S. Learning Factory: The Path to Industry 4.0. Procedia Manuf. 2017, 9, 73-80, doi:10.1016/j.promfg.2017.04.022.

65. H.; Duin, C.; Gorldt, K.T. and K.P. Learning In Ports With Serious Gaming. In Proceedings of the International Conference on Engineering, Technology and Innovation (ICE/ITMC) Funchal, Portugal, 27-29 June 2017; pp. 431-438, doi:10.1109/ICE.2017.8279917.

66. Papazoglou, M.P.; Andreou, A. Smart connected digital factories: Unleashing the power of industry 4.0 and the industrial internet. Cloud Computing and Services Science; Springer Verlag: Berlin, Germany, 2019; Volume 1073, pp. 77-101, doi:10.1007/978-3-030-29193-8_5.

67. Ashby, W.R. Requisite variety and its implications for the control of complex systems. In Facets of Systems Science; Part of the International Series in Systems Science and Systems Engineering; Springer: Berlin, Germany, 1991; Volume 7, pp. 405-417, doi:10.1007/978-1-4899-0718-9_28.

68. Engeström, Y. Activity theory and individual and social transformation. In Perspectives on Activity Theory; Cambridge University Press: Cambridge, UK, 1999; ISBN 0-521-43127-1.

69. Foot, K.A. Cultural-Historical Activity Theory as Practical Theory: Illuminating the Development of a Conflict Monitoring Network. Publ. Commun. Theory 2001, doi:10.1111/j.1468-2885.2001.tb00233.x.

70. Ashby, W.R. Variety, Constraint, and the Law of Requisite Variety; Wiley: Hoboken, NJ, USA, 2017; ISBN 15327000.

71. Clinton, G.; Lee, E.; Logan, R. Connectivism as a framework for creative productivity in instructional technology. In Proceedings of the 2011 IEEE 11th International Conference on Advanced Learning Technologies Athens, GA, USA, 6-8 July 2011; pp. 166-170, doi:10.1109/ICALT.2011.55.

72. Rodríguez, A.J.; Molero de Martins, D.M. Conectivismo como gestión del conocimiento. REDHECS Rev. Electrónica Humanidades, Educ. y Comun. Soc. 2009, 4, 73-85.

73. Vitali, I.; Arquilla, V.; Tolino, U. A Design perspective for IoT products. A case study of the Design of a Smart Product and a Smart Company following a crowdfunding campaign. Des. J. 2017, 20, S2592-S2604, doi:10.1080/14606925.2017.1352770.

74. Rajnai, Z.; Kocsis, I. Labor Market Risks of Industry 4.0, Digitization, Robots and AI. In Proceedings of the IEEE 15th International Symposium on Intelligent Systems and Informatics (SISY), Subotica, Serbia, 14-16 September 2017; pp. 000343-000346, doi:10.1109/SISY.2017.8080580.

75. Gualtieri, L.; Rojas, R.; Carabin, G.; Palomba, I.; Rauch, E.; Vidoni, R.; Matt, D.T. Advanced Automation for SMEs in the I4.0 Revolution: Engineering Education and Employees Training in the Smart Mini Factory Laboratory. In Proceedings of the IEEE International Conference on Industrial Engineering and Engineering Management (IEEM), Bangkok, Thailand 16-19 December 2018; pp. 1111-1115, doi:10.1109/IEEM.2018.8607719.

76. Jeganathan, L.; Khan, A.N.; Kannan Raju, J.; Narayanasamy, S. On a Frame Work of Curriculum for Engineering Education 4.0. In Proceedings of the 2018 World Engineering Education Forum-Global Engineering Deans Council (WEEF-GEDC), Albuquerque, NM, USA, 12-16 November 2018; pp. 1-6.

77. Tzafestas, S. Concerning human-automation symbiosis in the society and the nature. Int. J. Fact. Autom. Robot. Soft Comput. 2006, 1, 16-24.

78. Norman, D.A. El Diseño de los Objetos del Futuro. La Interacción Entre el Hombre y la Máquina.; Ediciones Paidós: Barcelona, Spain, 2010; ISBN 9788449323881.

79. Engeström, Y. The future of activity theory. In Learning and Expanding with Activity Theory; Cambridge University Press: Cambridge, UK, 2009, pp. 303-328, doi:10.1017/CBO9780511809989.020.

80. Squires, J.E.; Estabrooks, C.A.; Gustavsson, P.; Wallin, L. Individual determinants of research utilization by nurses: A systematic review update. Implement. Sci. 2011, 6, 43.

81. Allen, D.K.; Brown, A.; Karanasios, S.; Norman, A. How should technology-mediated organizational change be explained? A comparison of the contributions of critical realism and activity theory. MIS Quart. 2013, 37, 835-854. 
82. Hyysalo, S. Health Technology Development and Use: From Practice-Bound Imagination to Evolving Impacts; Routledge, Taylor \& Francis Group: New York, NY, USA, 2010; ISBN 0-203-84915-9.

83. Crawford, K., Hasan, H. Demonstrations of the activity theory framework for research in information systems. Australas. J. Inf. Syst. 2006, 13, 49-67, doi:10.3127/ajis.v13i2.40.

84. Engeström, Y. Expansive Learning at Work: Toward an activity theoretical reconceptualization. J. Educ. Work 2001, 14, 133-156, doi:10.1080/13639080020028747.

85. Sannino, A.; Engestrom, Y. Cultural-historical activity theory: Founding insights and new challenges. Cult. Hist. Psychol. 2018, 14, 43-56, doi:10.17759/chp.2018140304.

86. Henric-Coll, M. La Organización Fractal: El Futuro del Management; Fractal Teams: Navarra, Spain, 2014; ISBN 978-8461696628.

87. Jarzabkowski, P. Strategic practices: An activity theory perspective on continuity and change. J. Manag. Stud. 2003, 40, 23-56, doi:10.1111/1467-6486.t01-1-00003.

88. Kuutti, K. Activity theory as a potential framework for human-computer interaction research. In Context and Consciousness: Activity Theory and Human-Computer Interaction; The MIT Press: Cambridge, MA, USA 1995; pp. 17-44.

89. Wilson, T.D. Activity theory and information seeking. Annu. Rev. Inf. Sci. Technol. 2009, 42, 119-161, doi:10.1002/aris.2008.1440420111.

90. Issroff, K.; Scanlon, E. Using technology in higher education: An activity theory perspective. J. Comput. Assist. Learn 2002, 18, 77-83, doi:10.1046/j.0266-4909.2001.00213.x.

91. Benson, A.; Lawler, C.; Whitworth, A. Rules, roles and tools: Activity theory and the comparative study of e-learning. Br. J. Educ. Technol. 2008, 39, doi:10.1111/j.1467-8535.2008.00838.x.

92. Barab, S.; Schatz, S.; Scheckler, R. Using activity theory to conceptualize online community and using online community to conceptualize activity theory. Mind Cult. Act. 2004, 11, 25-47, doi:10.1207/s15327884mca1101_3.

93. Brine, J.; Franken, M. Students' perceptions of a selected aspect of a computer mediated academic writing program: An activity theory analysis. Australas. J. Educ. Technol. 2006, 22, 21-38, doi:10.14742/ajet.1305.

94. Blin, F. CALL and the development of learner autonomy: Towards an activity-theoretical perspective. ReCALL Cambridge Univ. 2004, 16, 377-395, doi:10.1017/S0958344004000928.

95. Abdullah, Z. Activity Theory as Analytical Tool: A Case Study of Developing Student Teachers' Creativity in Design. Procedia-Soc. Behav. Sci. 2014, 131, 70-84, doi:10.1016/j.sbspro.2014.04.082.

96. Hannah, Ji.; Hinson, L. Development of Propositions on Human Cognitive Abilities Matching Impacts on Accounting Job Performance. UF J. Undergrad. Res. 2019, 21, doi:10.32473/ufjur.v21i1.108723.

97. Beard-Gunter, A.; Ellis, D.G.; Found, P.A. TQM, games design and the implications of integration in industry 4.0 systems. Int. J. Qual. Serv. Sci. 2019, 11, 235-247, doi:10.1108/IJQSS-09-2018-0084.

98. Rodríguez, R.L. La Gestión del Tiempo Personal y Colectivo; Graó: Barcelona, Spain, 2010; ISBN 978-84-9980-406-4.

99. Arenas, T.; Martínez, M.Á.; Honggang, X.; Morales, O.; Chávez, M. Integrating VSM and Network Analysis for Tourism Strategies-Case: Mexico and the Chinese Outbound Market. Syst. Pract. Action Res. 2019, 32, 315-333, doi:10.1007/s11213-018-9475-6.

100. Hancock, P.A.; Jagacinski, R.J.; Parasuraman, R.; Wickens, C.D.; Wilson, G.F.; Kaber, D.B. Human-automation interaction research: Past, present and future. Ergon. Des. Q. Hum. Factors Appl. 2013, 21, 9-14, doi:10.1177/1064804613477099.

101. Sun, S.; Zheng, X.; Gong, B.; García, J.; Ordieres-Meré, J. Healthy Operator 4.0: A Human Cyber-Physical System Architecture for SmartWorkplaces. Sensors 2020, 20, doi:10.3390/s20072011.

102. Carrol, J. Human Cognitive Abilities: A Survey of Factor-Analytic Studies; Cambridge University Press: New York, NY, USA, 1993; ISBN 9780511571312.

103. Jordan, P.W. Designing Pleasurable Products: An Introduction to the New Human Factors; CRC Press: Boca Raton, FL, USA, 2000; ISBN 9780203305683.

104. Saritas, M.T. The Emergent Technological and Theoretical Paradigsn in Education: The Interrelations of Cloud Computing (CC), Conectivism and Internet of things (IoT). Proc. Acta Polytech. Hungarica 2015, 12, 161-179, doi:10.12700/APH.12.6.2015.6.10.

105. Downes, S. Connectivism and Connective Knowledge: Essays on Meaning and Learning Networks; National Research Council Canada: Ottawa, ON, Canada, 2012; ISBN 9781105778469. 
106. Salmon, G.; Siemens, G.; Ally, M. A Learning Theory for the Digital Age. Instr. Technol. Distance Educ. 2004, doi:10.1.1.87.3793.

107. Menary, R. The Extended Mind; A Bradford Book; The MIT Press: Cambridge, MA, USA, 2010; ISBN 978-0-262-01403-8.

108. Patel, P.; Ali, M.I.; Sheth, A. From Raw Data to Smart Manufacturing: AI and Semantic Web of Things for Industry 4.0. IEEE Intell. Syst. 2018, 33, 79-86, doi:10.1109/MIS.2018.043741325.

109. Cheng, Y.-J.; Chen, M.-H.; Cheng, F.-C.; Cheng, Y.-C.; Lin, Y.-S.; Yang, C.-J. Developing a Decision Support System (DSS) for a Dental Manufacturing Production Line based on Data Mining. In Proceedings of the IEEE International Conference on Applied System Invention (ICASI), Tokyo, Japan, 13-17 April 2018; pp. 638-641, doi:10.1109/ICASI.2018.8394336.

110. Wang, S.; Ouyang, J.; Li, D.; Liu, C. An Integrated Industrial Ethernet Solution for the Implementation of Smart Factory. IEEE Access 2017, 5, 25455-25462, doi:10.1109/ACCESS.2017.2770180.

111. Cagnin, R.L.; Guilherme, I.R.; Queiroz, J.; Paulo, B.; Neto, M.F.O. A Multi-agent System Approach for Management of Industrial IoT Devices in Manufacturing Processes. In Proceedings of the INDIN 2018: IEEE 16th International Conference on Industrial Informatics, Porto, Portugal, 18-20 July 2018; pp. 31-36, doi:10.1109/INDIN.2018.8471926.

112. Madsen, O., Møller, C. The AAU Smart Production Laboratory for Teaching and Research in Emerging Digital Manufacturing Technologies. Procedia Manuf. 2017, 9, 106-112, doi:10.1016/j.promfg.2017.04.036.

113. Lampón, J.F.; Cabanelas, P.; González-Benito, J. The impact of modular platforms on automobile manufacturing networks. Prod. Plan. Control. 2017, 28, 335-348, doi:10.1080/09537287.2017.1287442.

114. European Commission. Directorate-General for Research and Innovation. Defining Innovation. Report of the independent High. Level Group on Industrial Technologies; Directorate D-Industrial Technologies: Luxembourg, 2018; ISBN 978-92-79-85271-8.

115. Ryu, K., Jung, M. Agent-based fractal architecture and modeling for developing distributed manufacturing systems. Int. J. Prod. Res. 2003, 41, 4233-4255, doi:10.1080/0020754031000149275.

116. Lee, J.; Jin, C.; Bagheri, B. Cyber physical systems for predictive production systems. Prod. Eng. Res. Devel. 2017, 11, 155-165, doi:10.1007/s11740-017-0729-4.

117. Wu, D.; Ren, A.; Zhang, W.; Fan, F.; Liu, P.; Fu, X.; Terpenny, J. Cybersecurity for digital manufacturing. J. Manuf. Syst. 2018, 48, 3-12, doi:10.1016/j.jmsy.2018.03.006.

118. Suaily, S.; Zubaidah, S. Development of Product Service System Modelling in SMED: The Case of Inventory Control. J. Mod. Manuf. Syst. Technol. 2018, 1, 94-106.

119. Shin, M.; Mun, J.; Jung, M. Self-evolution framework of manufacturing systems based on fractal organization. Comput. Ind. Eng. 2009, doi:10.1016/j.cie.2008.09.014.

120. Wiltshire, T., Fiore, S.M. Social Cognitive and Affective Neuroscience in Human-Machine Systems: A Roadmap for Improving Trainig, Human-Robot Interaction and Team Performance. IEEE Trans. Human Machine Syst. 2014, 44, 779-787, doi:10.1109/THMS.2014.2343996.

121. Warneke, H.-J. The Fractal Company: A Revolution in Corporate Culture; Springer-Verlag: Berlin/Heidelberg, Germany, 1993; ISBN 978-3-642-78126-1.

122. Ávila-Gutiérrez, M.J.; Aguayo-González, F.; Marcos-Bárcena, M.; Lama-Ruiz, J.R.P.-Á. Reference holonic architecture for sustainable manufacturing enterprises distributed. DYNA 2017, 84, 160.

123. Hübner, I. RAMI 4.0 und die Industrie-4.0-Komponente. Open Automation 2015, 24-29.

124. Yao, X.; Lin, Y. Emerging manufacturing paradigm shifts for the incoming industrial revolution. Int. J. Adv. Manuf. Technol. 2016, doi:10.1007/s00170-015-8076-0.

125. Johannessen, J.-A. Knowledge Management and Organizational Learning. In Knowledge Management as a Strategic Asset; Emerald Publishing: Bingley, UK, 2018; ISBN 978-1-4419-0007-4.

126. Li, H.; Williams, T.J. Interface design for the Purdue enterprise reference architecture (PERA) and methodology in e-Work. Prod. Plan. Control. 2003, 14, 704-719, doi:10.1080/09537280310001647841.

127. Williams, T. The Purdue Enterprise Reference Architecture and Methodology (PERA); Kluwer Academic: Dordrecht, The Netherlands, 1998; ISBN 412812509.

128. Odewale, A. Implementing secure architecture for industrial control systems. In Proceedings of the 27 th COREN Engineering Assembly, Abuja, Nigera, 6-8 August 2018; p. 17. 
129. Plósz, S.; Hegedüs, C.; Varga, P. Advanced security considerations in the arrowhead framework. In Proceedings of the Intelligent Tutoring Systems, Trondheim, Norway, 20-23 September 2016; Springer Science and Business Media LLC: Berlin, Germany; Volume 9923, pp. 234-245.

130. Larrinaga, F.; Aldalur, I.; Illarramendi, M.; Iturbe, M.; Perez, T.; Unamuno, G.; Lazkanoiturburu, I. Analysis of technological architectures for the new paradigm of the Industry 4.0. Dyna 2019, 94, 267-271, doi:10.6036/8837.

(c) (i)

(C) 2020 by the authors. Licensee MDPI, Basel, Switzerland. This article is an open access article distributed under the terms and conditions of the Creative Commons Attribution (CC BY) license (http://creativecommons.org/licenses/by/4.0/). 